\title{
POLÍTICAS ESTATALES Y SU REPERCUSIÓN EN LA VITIVINICULTURA DE LA PROVINCIA DE MENDOZA Y DEL MUNICIPIO DE SAN RAFAEL, 1946-1955
}

\author{
STATE POLICIES AND THEIR IMPACT ON THE \\ VITICULTURE OF THE PROVINCE OF MENDOZA AND \\ THE MUNICIPALITY OF SAN RAFAEL, 1946-1955
}

\author{
Ivana Hirschegger* \\ Universidad Nacional de Cuyo, Mendoza, Argentina, <ivanah@mendoza-conicet.gob.ar>
}

\begin{abstract}
Resumen. El presente trabajo se inserta en aquellas líneas de investigación que estudian el peronismo en el interior del país y en particular las políticas económicas implementadas en ese ámbito. Tiene por objetivo analizar las políticas públicas destinadas a una de las actividades agroindustriales más importantes de la provincia de Mendoza: la vitivinícola. De esta manera, la investigación pretende contribuir al avance del conocimiento acerca de las características y particularidades de la historia de las economías regionales argentinas y a profundizar el debate académico sobre el tema.
\end{abstract}

Palabras clave: políticas estatales, vitivinicultura, economía regional.

Abstract. The present work is inserted within those lines of investigation that study the Peronism inside the country in particular and the implemented economic policies in that scope, and must by objective analyze the public policies destined to one of the more important agro-industrial activities of the province of Mendoza: the wine producing one. This way, the investigation tries to contribute to the advance of the knowledge about the characteristics and particularities of the history of the Argentine regional economies and to deepen the academic debate on the thematic one.

Key words: state policies, wine, regional economy.

Fecha de recepción: septiembre de 2011. Fecha de aceptación: diciembre de 2011.

* Agradecemos las correcciones y sugerencias emitidas por los evaluadores, ya que han contribuido al avance y mejora de la presente investigación.

Am. Lat. Hist. Econ., año 19, núm. 3, septiembre-diciembre, 2012, pp. 57-97 


\section{INTRODUCCIÓN}

i bien los estudios sobre el periodo 1946-1955 han avanzado con-
siderablemente en las últimas dos décadas en Argentina, existe un
vacío historiográfico en cuanto a las economías provinciales, ya que a
pesar de que las nuevas líneas de investigación estudian el peronismo en el
interior del país, enfatizan más en los aspectos político-administrativos de
las provincias ${ }^{1}$ que en los procesos económicos producidos en esos ámbi-
tos. $^{2}$ El estudio de la repercusión de las políticas públicas peronistas sobre
una de las principales actividades económicas de la provincia de Mendoza como es la vitivinícola, intenta cubrir esta escasez de investigaciones so-
bre la época en los espacios provinciales ${ }^{3}$ y, al mismo tiempo, contribuir
a profundizar el conocimiento de la historia de las economías regionales
argentinas.

Desde comienzos del siglo xx hasta la década de 1970, el modelo vitivinícola en Argentina no tuvo variaciones, manteniéndose características como la gran producción de baja calidad, un mercado nacional altamente protegido y fuerte intervención estatal -en su mayor parte nacional- para atenuar numerosas y reiteradas crisis. El crecimiento económico generado en el país por la industrialización sustitutiva de importaciones fue acompañado por el viñedo desde 1945, cuya expansión se prolongó hasta la segunda mitad de la década de 1970. En ocasiones, el granizo y las heladas moderaban la oferta de uvas y contribuían a equilibrar la producción y el consumo, pero otras crisis implicaron cambios forzados, así como la intervención de los gobiernos de la región transformando a sus estados en empresarios. En definitiva, en esta etapa, el mercado vitivinícola sufrió las más variadas regulaciones. ${ }^{4}$ En otros países de América Latina, como por ejemplo Chile, el vino se mantuvo durante mucho tiempo como un

${ }^{1}$ En esta línea transitan la mayoría de los trabajos compilados por Macor y Tcach, Invención, 2003; Melon y Quiroga, Peronismo, 2006; Rubinstein, Sindicatos, 2006, entre otros.

${ }^{2}$ Entre los escasos trabajos se destacan el de Noemí Girbal-Blacha sobre la política crediticia a las industrias tradicionales como la azucarera y la vitivinícola. Véase Girbal-Blacha, Mitos, 2003. Respecto a la industria azucarera durante el peronismo, véase también Girbal-Blacha, "Economía", 2003. Sobre la vitivinicultura en la provincia de San Juan durante el gobierno peronista, véanse Borcosque, "Empresarios", 2008, y "Accionar", 2009. La acción del Estado peronista en la industria vitivinícola y los efectos sobre una entidad empresarial como fue la Asociación Vitivinícola Argentina (en adelante AVA), véanse en Mateu y Olguín, "Problema", 2006.

${ }^{3} \mathrm{La}$ industria vitivinícola en el siglo XIX y principios del XX y desde diferentes perspectivas es estudiada por Barrio, "Controles”, 2010. También, Barrio, Crisis, 2010, y Hacer, 2010; Cantarelli, "Contratistas", 2011; Pérez, Más, 2010, y Guardianes, 2008; Richard-Jorba, Poder, 1998; Empresarios, 2010, y Rodríguez, "Desarrollo”, 2009, y “Educación”, 2011.

${ }^{4}$ Desde la década de 1960 fueron conformando una legislación heterogénea y contradictoria, lo que produjo distorsiones permanentes en el mercado durante casi cuatro décadas y problemas cada vez más graves. Richard-Jorba, “Crisis”, 2008, pp. 91-93. 
producto de consumo interno, sin que las exportaciones lograsen alcanzar niveles significativos durante más de un siglo. Al igual que en Argentina, para enfrentar situaciones de crisis, el Estado intervino en la agroindustria mediante la imposición de nuevos marcos legales, cuyo objetivo básico fue, en algunos momentos, como por ejemplo a fines de la década de 1930, limitar la producción y obtener mejores precios. Sin embargo, este tipo de disposiciones, que tuvieron vigencia durante un largo tiempo, produjo una evolución negativa de la vitivinicultura en el periodo 1938-1972, ya que hicieron que la superficie plantada y la producción crecieran muy poco o nada durante la mayor parte del periodo. ${ }^{5}$

Centrándonos en la provincia de Mendoza, durante la crisis vitivinícola de la década de 1930, caracterizada por una sobreproducción de vino, el Estado intervino en la industria a través de políticas reguladoras. La Ley nacional núm. 12137 de 1935 creó la Junta Reguladora de Vinos, y la Ley núm. 12139 unificó los impuestos internos nacionales y provinciales al consumo, incluyendo el vino. En 1938 se dictó la Ley General de Vinos núm. 12 372, creando la Dirección General de Vitivinicultura en el ámbito del Ministerio de Agricultura. Las principales acciones giraron en torno a la disminución de la oferta mediante la prohibición de plantar nuevos viñedos, la destrucción de las viñas ${ }^{6}$ y la compra de excedentes del vino producido para mantener o aumentar los precios desvalorizados. ${ }^{7}$ A fines de la década de 1940, la industria vitivinícola sufriría nuevamente un desequilibrio, pero esta vez caracterizado por la escasez de producción frente al crecimiento de la demanda de vino, resultado de la política salarial aplicada por el gobierno con el objetivo de mejorar el poder adquisitivo de la población, situación que en el mercado producía un aumento del precio del producto.

Bajo este nuevo contexto y frente a un Estado dirigista y planificador como fue el peronista, ${ }^{8}$ que disponía de la protección y fomento de aquellas industrias elaboradoras de materias primas nacionales, entre las

\footnotetext{
${ }^{5}$ Véase Pozo, Historia, 1998, pp. 183-236.

${ }^{6}$ Se eliminaron 17000 ha de viñas en la década de 1930, lo que congeló la superficie cultivada. De 100619 ha existentes en 1936 se pasó a 83605 en 1938, manteniéndose este valor hasta 1944. Richard-Jorba, "Formación”, 2006, pp. 97-98.

${ }^{7}$ Véase Ospital, "Políticas", 2005. Sobre este tema véanse también Girbal-Blacha et al., Miradas, 2007, y Mateu, "Vitivinicultura", 2005. Las políticas distribucionistas (mejora del ingreso de la población) y de expansión del mercado interno y los niveles de consumo, pronto mostraron la incongruencia de mantener la prohibición de implantar nuevos viñedos, por lo tanto, la medida fue levantada por el gobierno militar en 1944, apuntando a incrementar la oferta para mantener controlados los precios de un bien importante en la dieta de la población de la época.

${ }^{8}$ Girbal-Blanca, "Políticas", 2002. El gobierno peronista modificó el modelo de desarrollo que Argentina había asumido a fines del siglo XIX, poniendo énfasis en el mercado interno y en la industrialización, mediante la introducción de innovaciones institucionales y la aplicación de nuevos instrumentos de promoción, en Belini, "Estado", 2004, p. 73.
} 
cuales se incluían las radicadas en la región cuyana y dedicadas al ramo alimenticio, ${ }^{9}$ nos proponemos observar el accionar de dicho Estado en la industria vitivinícola provincial. Esto hace necesario centrar la mirada sobre distintas formas de intervención; es decir, la destinada a resolver cuestiones concretas o coyunturales, como fue el precio del vino y la orientada a solucionar problemas de fondo, mediante el estímulo de la producción (primaria e industrial). Aunque nuestro objetivo central es observar el efecto de las estrategias estatales en el crecimiento de la actividad vitivinícola, el análisis de estas nos permitirá descubrir no sólo las transformaciones del papel del Estado en materia económica, sino también aproximarnos a la relación entre este y los distintos agentes que integran la actividad, en el sentido de verificar hacia dónde fueron dirigidas las políticas y cuáles fueron subsectores que recibieron el apoyo del Estado. ${ }^{10}$

Cabe destacar que el análisis no se limita a observar la industria en la provincia en su conjunto, sino que realizamos un estudio de casos en el que se realizará un primer acercamiento al comportamiento de la vitivinicultura, a partir de las políticas estatales, de uno de los municipios que forman parte del oasis sur de la provincia de Mendoza, San Rafael. ${ }^{11}$ La elección de este se fundamenta en el hecho de constituir uno de los núcleos de desarrollo de la provincia y la importancia adquirida por la vitivinicultura -y otras industrias de base agrícola- que lo ubica como uno de los lugares más destacados dentro de la economía provincial. En definitiva, nos proponemos observar en qué medida el gobierno peronista contribuyó al desarrollo de la agroindustria de uno de los municipios más importantes de la provincia de Mendoza. La relevancia de San Rafael en nuestro estudio debe ser resaltada mediante una referencia paralela a la provincia tomada en su conjunto y, mientras lo permitan las fuentes, a un departamento de características distintas, como es Lavalle, ubicado en el oasis norte y de menor desarrollo relativo. El análisis comparativo no sólo permitirá medir el grado de importancia adquirida por San Rafael, sino también obtener un panorama de la distribución territorial o espacial de las políticas económicas llevadas a cabo por el Estado nacional y provincial.

\footnotetext{
${ }^{9}$ Presidencia, Primer, 1947, p. 359, y Segundo, 1953, p. 201, y Girbal-Blacha, "Economía", 2003, p. 43.

${ }_{10}$ El tema de la injerencia estatal en las relaciones laborales durante el peronismo en Mendoza escapa a nuestra investigación. Para esta problemática véanse Garzón, "Hermosa", 2010, "Dispersión", 2011, y Relaciones, 2011.

${ }^{11}$ Como se trata de una investigación en curso, esta temática se profundizará en futuros trabajos.
} 


\section{EL DESEQUILIBRIO VITIVINÍCOLA Y LA APLICACIÓN DE PRECIOS MÁXIMOS}

A fines de la década de 1940, la industria vitivinícola presentó un desequilibrio en el que la producción de vino descendió abruptamente frente al aumento progresivo de la demanda (véase gráfica 1). El descenso de la cantidad de vino tuvo relación directa con la caída de la producción de uva, disminución que tuvo que ver principalmente con los fenómenos climáticos, tal como lo veremos más adelante.

Respecto al consumo de vino per cápita en todo el país, su aumento (de 51 litros en 1946 a 69 litros en 1949) se debió, entre otras cosas, a las políticas salariales expansivas destinadas a mejorar el nivel de vida de la población, ${ }^{12}$ aunque tendió a decrecer entre 1950 y 1951 , ya que el proceso inflacionario había superado la tasa de aumento salarial, y como consecuencia, disminuyó el poder adquisitivo de la población. ${ }^{13}$ Sin embargo, a partir de 1952 el consumo se recuperaría por el mejoramiento de la situación económica (llegando a 59 litros per cápita). ${ }^{14}$

Como veremos en el presente apartado, el Estado enfrentó la situación de desequilibrio mediante medidas coyunturales o de emergencia entre las cuales se destaca la fijación de precios máximos. Si bien no es nuestro objetivo profundizar acerca de la repercusión de estas políticas sobre los distintos agentes participantes, intentaremos acercarnos a los cambios producidos en el comportamiento de los actores que integran la industria. Para ello, y con base en la tipología de Richard-Jorba,${ }^{15}$ destacamos en nuestro periodo de estudio la presencia del viñatero (propietario o arrendatario) que vendía su producción en el mercado de uvas o elaboraba en bodegas de terceros. Por otra parte, se encontraba el productor agroindustrial, el cual lo podemos dividir en dos tipos: el pequeño, que compraba o elaboraba uvas y producía vino de traslado, generalmente controlado por las grandes bodegas o por mayoristas de Buenos Aires y el Litoral, los cuales a la vez fijaban las condiciones de precios y modalidades de pago; y el

\footnotetext{
${ }^{12}$ Por ejemplo, el índice del salario real de los trabajadores aumentó entre 1945 y 1950 a $72 \%$. A este aumento del ingreso, cabe agregar el crecimiento de la población, un claro ejemplo es la población de la provincia de Mendoza entre 1947 y 1952 la cual aumentó alrededor de 27\%, véanse Dirección, IV Censo, 1947, pp. 284-285; Anuario, 1953, p. 50, y 1957, p. 29.

${ }^{13}$ Por ejemplo, en 1951 el índice del costo de vida registró un aumento de $37 \%$ respecto al año anterior, mientras que el de los precios mayoristas fue de 48\%, en Ferrer, Economía, 2004, p. 228.

${ }^{14}$ El nuevo programa económico incluyó una severa política de ingresos, con la creación de la Comisión Nacional de Precios y Salarios, la concertación de convenios laborales bianuales, y un estricto control de precios. Así, el repunte de la producción agropecuaria de la campaña 19521953 y el aumento de las importaciones, permitió el aumento de los precios a 4\% anual en 1954 y una leve recuperación del nivel de la actividad productiva. La política de ingresos logró evitar la caída sustancial en los salarios reales y mantener la participación de los trabajadores en el ingreso nacional. Ibid., pp. 228-229.

${ }^{15}$ Richard-Jorba, Poder, 1998.
} 
GRÁFICA 1. PRODUCCIÓN DE UVA Y VINO, CONSUMO LOCAL Y SALIDA DE LA PROVINCIA, MENDOZA, 1946-1953

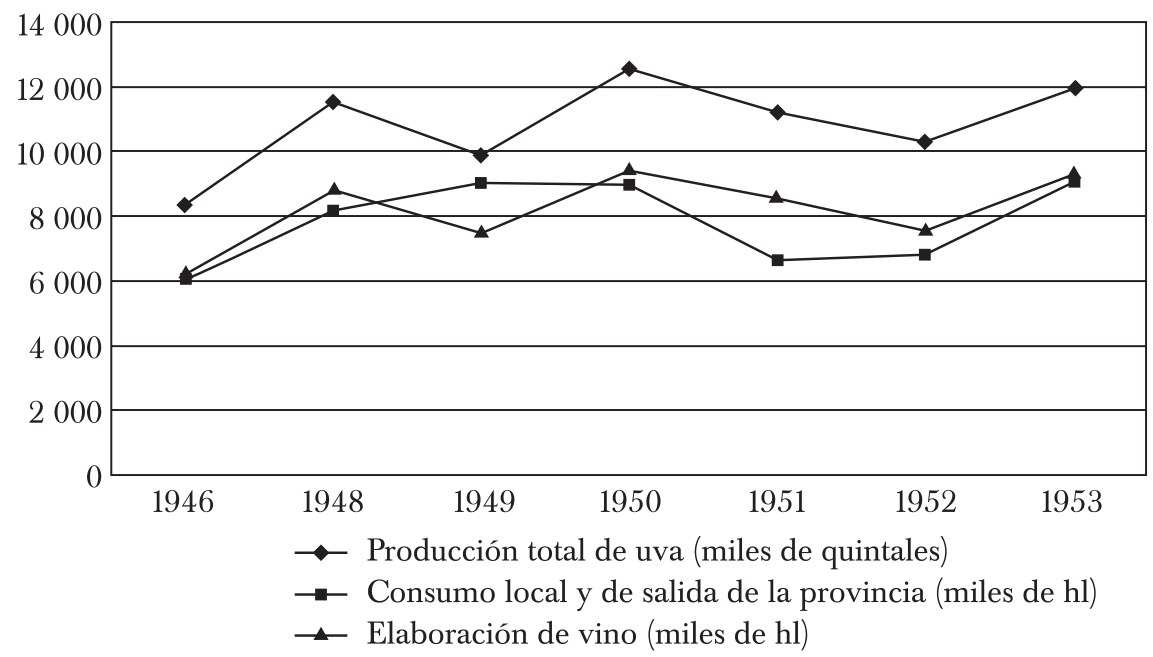

Fuente: elaboración propia con base en datos del Anuario, 1954.

grande, integrado verticalmente dada su condición de viñatero, trasladista, fraccionador y comerciante. Sin embargo, en ciertos momentos, cuando el precio del vino no aseguraba buena rentabilidad, este subsector compraba vino de traslado a las pequeñas bodegas. Este agente formaba parte de un grupo reducido con capacidad para controlar la industria e intervenir en la fijación de precios. También se verifica la radicación de plantas fraccionadoras en los grandes centros de consumo del país, que con frecuencia no tenían vinculación societaria con los eslabones de producción primaria o de industrialización, favoreciendo la adulteración de caldos y el fraude.

Retomando el tema del "ordenamiento vitivinícola", en un principio, el gobierno nacional estableció precios máximos sólo para el vino destinado directamente al consumo, los cuales se fueron modificando periódicamente. En realidad, medidas como estas habían sido aplicadas en 1945 cuando la inflación alcanzó $17.6 \%$, año en que el precio de venta de vino común al consumidor se retrotrajo al vigente en la primera quincena del mes de diciembre de 1944: 0.50 pesos por litro, disposición que formaba parte de una política general destinada a los bienes de consumo de primera necesidad. ${ }^{16}$ En 1946, cuando la inflación acumulada anual llegó a 13.2\%,

${ }^{16}$ Mateu y Olguín, "Problema”, 2006, p. 16. 
el poder ejecutivo nacional autorizó un aumento de $60 \%$ en relación con el precio establecido anteriormente. Así, el precio del vino común por litro llegó a 0.75 pesos para vinos sueltos; 0.80 pesos para envasados (tintos, claretes o criollos), y 0.85 pesos los blancos secos. ${ }^{17}$

En un informe de la Asociación Vitivinícola Argentina (AVA) enviado al Consejo Económico Nacional y a la Secretaría de Industria y Comercio, se explicaba que con el precio tope fijado por el gobierno para la venta del vino al consumidor no era posible aumentar los ingresos de las diferentes ramas de la industria. En realidad, la AVA hizo fuertes críticas y reclamos a la intervención en los precios por parte del Estado ${ }^{18}$ "volviéndose cada vez más frecuentes a medida que aumentaban los índices de inflación y las modificaciones de los precios máximos tornaban nuevamente insignificante el aumento permitido". ${ }^{19}$ Según el informe emitido por el citado organismo, en 1946 los ingresos brutos de los industriales eran similares o inferiores a los del periodo 1930-1934, mientras que los gastos en materiales, fletes y salarios habían aumentado considerablemente. En defensa de los fraccionadores, el organismo señaló que a diferencia de los bodegueros trasladistas y viñateros (no sujetos a controles hasta ese momento), ${ }^{20}$ habían visto reducido su margen de ganancia en $27 \%$ entre 1944 y 1947 , principalmente por el aumento del flete del ferrocarril entre Mendoza y Buenos Aires (9\%), el costo de las botellas (73.7\%), el de los corchos (19\%) y el salario promedio (105.4 por ciento). ${ }^{21}$

A fines de 1948, los precios máximos fueron extendidos también a la uva y el vino de traslado. Por el Decreto nacional núm. 39493 se modificaron nuevamente los precios máximos a la venta de vinos comunes en la Capital Federal y algunas zonas de Buenos Aires y para la provincia de Mendoza y San Juan. Para estas dos provincias, el gobierno nacional fijó los precios máximos a la uva de vinificar en 25 pesos el quintal puesto en bodega y al vino de traslado en 0.41 pesos el litro (vino tinto, claretes, criollos y blancos) ${ }^{22}$ Pero una vez determinados los precios de la uva y el vino de traslado por el Estado en ese año, no tardaron en alzarse voces

${ }^{17}$ Precios máximos de venta del vino al consumidor fijado en el Decreto núm. 3134 del Poder Ejecutivo Nacional. Asociación de la Industria Vitivinícola Argentina, Revista Vinos, Viñas y Frutales, 1946, pp. 450 y 451.

${ }^{18}$ Véanse Asociación, "Problemas", 1947, pp. 161-162, y "Pedido", 1948, pp. 380-383.

${ }^{19}$ La reacción de la AVA frente a las políticas estatales ha sido estudiada por Mateu y Olguín, "Problema", 2006.

${ }^{20} \mathrm{El}$ margen de venta para los fraccionadores es la diferencia entre el precio del vino al por mayor en la capital federal y el precio sobre vagón en Mendoza, y el de los bodegueros trasladistas la diferencia entre el precio del vino sobre vagón en Mendoza y el de la uva en Asociación, "Problemas", 1947, pp. 161-162.

${ }^{21}$ Ibid.

${ }^{22}$ Quedaban exceptuados los vinos elaborados con uvas de variedades finas y vinos de tipos especiales. 
destacando el perjuicio que ello representaba para los sectores elaboradores de ambos productos, ya que se trataba de precios inferiores a 1947 (véase cuadro 1).

Uno de los actores que integran la industria, como eran los viñateros -a través de la Federación de la Industria Vitivinícola- solicitaron al presidente de la nación la reconsideración de las medidas sancionadas, dado el aumento producido en las cotizaciones de la materia prima que regían todas las etapas de la industria. Así, se sostenía que desde la sanción del Decreto nacional 39493 en 1948, todos los costos habían experimentado un aumento (contribución directa, impuesto a las actividades lucrativas, materiales, abonos, herramientas, alimentación de animales, etc.), situación que no permitía a los cultivadores obtener una retribución justa, lo que junto a otros factores (contingencias climáticas, plagas, etc.) incidían en la producción de la materia prima. ${ }^{23}$

En respuesta a estos reclamos, entre 1949 y 1950 se produjeron incrementos en el precio de la uva en un $10 \%,{ }^{24}$ liberándolos en 1951. Sin embargo, la liberación no incluyó el vino de traslado y de consumidor final, ya que debía prohibirse y eliminarse todo factor especulativo en la comercialización de la uva, y con ello, evitar el alza artificial de los precios. ${ }^{25}$ En el cuadro 1 se puede observar los aumentos del precio del vino fijado por el Estado entre 1949 y 1951 (60\% para el vino de traslado y 30\% para el de botella). Respecto al vino de consumo final, debemos destacar que era fijado ahora por el gobierno de la provincia, en virtud de las atribuciones concedidas por el decreto nacional arriba mencionado. ${ }^{26}$

A pesar de estos aumentos, los mismos continuaron siendo insuficientes para cubrir los costos de producción, con mayores perjuicios para los pequeños productores agroindustriales (trasladistas), ya que el precio tope fijado al vino elaborado por estos (alrededor de 0.70 pesos el litro en 1951) no guardaba relación con los precios del vino al consumo. La diferencia entre ambos actores económicos radicaba en que mientras el comprador de la producción de las pequeñas bodegas tenía "manos libres" para fijar los precios al consumo y realizar mezclas, aguamiento, etc., el pequeño elaborador debía producir vino genuino y venderlo a un precio del cual no podía evadirse. Por ejemplo, a principios de la década de 1950 cualquier

23 "Una razonable solicitud relacionada con el precio de la uva", Los Andes, 3 de marzo de 1949 , p. 4, y 11 de diciembre de 1951, p. 3.

${ }^{24}$ Sólo hemos tomado este periodo para calcular el porcentaje de aumento porque en 1951 el Estado dejó de fijar precios máximos a la uva.

${ }^{25}$ Considerandos del Decreto núm. 7168 en Boletín, 1951, p. 168.

${ }^{26}$ Que establecía que en el resto del país, los precios de venta de los vinos comunes de mesa serían determinados por los gobiernos de las provincias y de territorios, en arts. 7 y 8 del Decreto núm. 39493 del 29 de diciembre de 1948, en Anales, 1955, pp. 490-491. 
Am. Lat. Hist. Econ., año 19, núm. 3, septiembre-diciembre, 2012, pp. 57-97

CUADRO 1. PRECIO DE LA UVA, VINO DE TRASLADO

Y EN BOTELLA, 1947-1951 (PESOS ARGENTINOS)

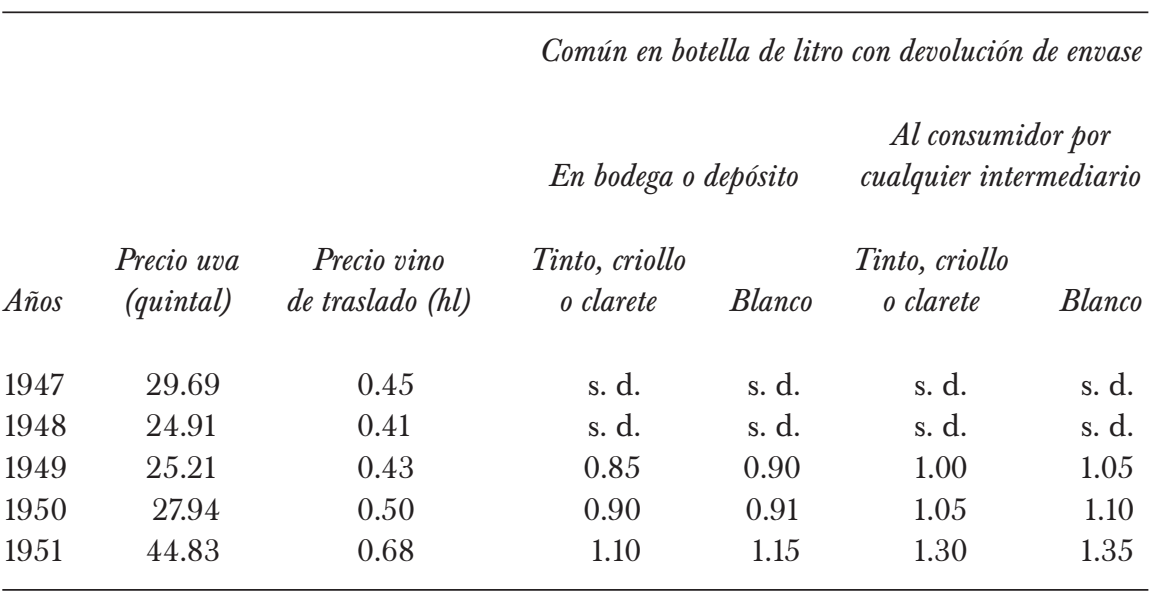

Nota: s. d. $=$ sin datos.

Fuentes: elaboración propia con base en datos del Anuario, 1952, pp. 58-59; Decreto núm. 1 768, en Boletín, 1949, p. 1 363; Decreto núm. 346, en Boletín, 1950, p. 602; Decretos núms. 5 y 7 168, en Boletín, 1951, pp. 856 y 168, respectivamente.

vino aguado costaba tres pesos el litro. Entre este precio y tope de 0.70 pesos fijado al vino de traslado había una diferencia con la cual el gran bodeguero cubría sus costos, obteniendo de esta manera mayores ganancias. Estas prácticas ilegales por parte de los grandes bodegueros pueden corroborarse a través de las denuncias realizadas por la prensa. El diario Los Andes destacó en repetidas oportunidades las maniobras fraudulentas seguidas por los bodegueros en contra de las normas básicas a que debía ajustarse la vinificación como cortes de vino, empleo de sustancias con las que se aumentaba y estiraba artificialmente el volumen de la producción. El otro hecho ocurrido era la violación de los precios máximos del vino en botella, vendiéndolos a precios superiores a los establecidos por el Estado, ${ }^{27}$ que debían costar entre 1.10 y 1.35 según el tipo de vino (cuadro 1). Sin duda alguna, estas prácticas tenían que ver en cierta medida con la falta de control oficial de la comercialización del producto, en este caso por parte de la Dirección de Vigilancia de Precios y Abastecimientos, aunque no es un tema sobre el cual ahondaremos. Según la opinión de Benito

27 "Las cuotas de expendio y el fraude en la vinicultura", Los Andes, 22 de julio de 1951, p. 4; "El rendimiento de la producción vínica y la especulación actual”, Los Andes, 18 de septiembre de 1951, p. 3, y "Graves problemas de la economía mendocina”, Los Andes, 25 de enero de 1952, p. 3. 
Marianetti, ${ }^{28}$ estas políticas significaron la "liquidación" de los pequeños productores ${ }^{29}$ frente a los enormes beneficios que obtenían los grandes bodegueros y comerciantes. ${ }^{30}$

Una de las consecuencias de esta situación fue, en ciertas ocasiones, la falta de aprovisionamiento de vino de traslado, frente a lo cual y con el objetivo de abastecer de vino a la población, se dictaron otras medidas como la fijación de cuotas para la expedición de vinos (a los precios fijados por el Estado) y, en 1949, se declaró la expropiación de todas las partidas de vinos comunes de mesa de las provincias de Mendoza y San Juan en poder de bodegas trasladistas y "exportadoras" que no operaron en ese carácter el año anterior ${ }^{31}$ y se creó una comisión mixta de fiscalización y autorización de compra y expendio. ${ }^{32}$ En la segunda etapa del gobierno peronista, la gran mayoría de los productores agroindustriales (trasladistas), que durante años habían elaborado su propia producción de uvas o la adquirida de terceros, cerraron sus puertas, ya que teniendo en cuenta el bajo precio asignado por vía oficial al vino de traslado, vendían sus uvas a los grandes establecimientos. Los datos publicados por el gobierno de Mendoza permiten corroborar esta afirmación, ya que en 1951 sólo elaboraron $70 \%$ de las bodegas existentes, porcentaje que se redujo en diez puntos al año siguiente. ${ }^{33}$

A finales del gobierno, y como veremos más adelante, el hecho de que la mayor parte de los viñateros se encontraran en manos de un grupo reducido de grandes bodegueros (lo cual producía especulación en cuanto al precio de la uva), tuvo como consecuencia una fuerte intervención del gobierno en los mercados vitivinícolas, reflejándose la participación empresarial que fue adquiriendo el Estado.

\section{RESEÑA SOBRE ALGUNAS CARACTERÍSTICAS DE LOS DEPARTAMENTOS SELECCIONADOS}

Para acercarnos a la repercusión que tuvieron las políticas públicas en el departamento de San Rafael, se hace necesario, como sostuvimos en la introducción, realizar un análisis comparativo con la provincia tomada

${ }^{28}$ Uno de los máximos exponentes del Partido Comunista de la provincia de Mendoza.

${ }^{29}$ Marianetti, Cuestión, 1952, p. 29.

${ }^{30}$ Por ejemplo, entre 1949 y 1950 los ingresos de la bodega El Globo aumentaron casi $50 \%$ y los de El Trapiche, 186\%. Las ganancias de la Sociedad Gabrielli y Baldini aumentaron 360\% entre 1948 y 1950; en Boletín de Economía, editado por el Partido Comunista y citado en Marianetti, Cuestión, 1952, pp. 63-64.

31 "Decreto núm. 5 851", 1949, p. 223.

${ }^{32}$ Borcosque, "Empresarios", 2008, p. 98.

${ }^{33}$ Anuario, 1953, pp. 63-64. 
en su conjunto y con un municipio de características diferentes como fue Lavalle.

Hacia 1947, el departamento de San Rafael era el más poblado de la provincia después de la capital, representando $16 \%$ de la población total (97 000 habitantes), en cambio, Lavalle se caracterizaba por su escasa población, alcanzando sólo 4\% de la provincia (14 000 habitantes). ${ }^{34}$

En cuanto a los recursos hídricos, el territorio de San Rafael es recorrido por dos ríos: el Diamante y el Atuel, cuyos cursos son los más aprovechados de la provincia. Participa de las características generales de toda la provincia con lluvias insuficientes, lo que no permite cultivos sino mediante riego artificial. Esto hace que la superficie irrigada represente alrededor de $3.5 \%$ de todo el departamento y es allí donde se concentra la mayor cantidad de población (95\%). Lavalle pertenece a la cuenca hídrica del río Mendoza, aunque su ubicación en la parte inferior es una de las causas de la mayor falta de agua en este departamento. Su clima árido influye en su organización territorial y en el asentamiento de su población. Dada la escasez de precipitaciones, el espacio se encuentra organizado en función de la estructura de la red hídrica -red de canales-, ${ }^{35}$ que riega solamente 3\% de la superficie departamental. En ambos departamentos, la superficie no regada es denominada área de secano o popularmente "desierto", donde se asienta una población dispersa. A esta población se la denomina "puesteros", dedicados fundamentalmente a la cría de ganado.

Entre las actividades económicas, la industria -en sus distintos tiposocupaba un lugar destacado en San Rafael, no sólo por el número de establecimientos (610) y personal ocupado (1 111), sino, además, por su significación en la economía provincial. ${ }^{36}$ Fue el municipio con mayor número de establecimientos industriales, frente a los 19 del departamento de Lavalle y los 16 empleados que registra el censo industrial de $1946 .{ }^{37}$ En este último departamento existían establecimientos de tipo familiar y artesanal y no verdaderas industrias. Otro factor que contribuía a la economía del departamento sanrafaelino era el comercio, siendo esta circunscripción la de mayor número de establecimientos comerciales (1 121), personal ocupado (3 255) e ingresos percibidos (46 334 pesos), después de la capital de

\footnotetext{
${ }^{34}$ Dirección, IV Censo, 1947, p. 290.

${ }^{35}$ Véase García y Molina, "Hacia", 1993, pp. 192-193.

${ }^{36}$ Representó $17 \%$ de los establecimientos y $12.7 \%$ de los empleados de toda la provincia, en Dirección, IV Censo, 1947, p. 77.

${ }^{37}$ Ibid. Dada la poca cantidad de establecimientos, el personal ocupado debe haber sido escaso. Sin embargo, creemos que los datos proporcionados por el censo son erróneos, ya que el hecho de existir sólo 16 personas ocupadas significaría la inexistencia de empleados en algunas fábricas. Lo más probable es que se haya censado sólo al personal asalariado y no se haya incluido al propietario y su familia; que seguramente trabajaban en esas unidades.
} 
la provincia. ${ }^{38}$ En cambio, en Lavalle sólo existían 119 comercios, todos muy pequeños, caracterizándose también por el escaso personal ocupado (35) y los bajos ingresos percibidos (326 pesos). ${ }^{39}$

En San Rafael, la agricultura era el basamento de toda la actividad económica, siendo la viticultura su principal rama. Por su parte, Lavalle es un departamento netamente agropecuario con escaso desarrollo de otras actividades económicas. Aunque su principal actividad estuvo relacionada con la producción agrícola primaria (vid, frutas, alfalfa), tenía escasa representación para Mendoza. Por ejemplo, en 1947, del total de la superficie cultivada, sólo $5 \%$ pertenecía a Lavalle, ${ }^{40}$ frente a $28 \%$ que tenía San Rafael. El valor de la industria vitivinícola, en uno y otro departamento, se manifestaba a través de los viñedos plantados y del vino producido. En San Rafael, el área cultivada con viñedos era de 16103.40 ha y representaba $15 \%$ de la superficie vitícola de la provincia, ocupando el segundo lugar después del departamento de Maipú (Oasis Norte). La uva vinificada -comprada y propia- llegó a 1694368 quintales, es decir, 18.5\% del total provincial; con ella se produjo $1292983 \mathrm{hl}$ de vino (14\% del total provincial). ${ }^{41}$ Las bodegas, en total 216 , ocupaban un lugar preponderante en la riqueza y producción del departamento. Menor importancia tuvo la industria vitivinícola de Lavalle respecto a la provincia. El área cultivada con viñedos era de 5444 ha, representando sólo 5\% de la superficie vitícola total frente a $15 \%$ de San Rafael que acabamos de mencionar. La uva vinificada -comprada y propia- llegaba a 25206 quintales $(0.2 \%$ del total provincial), produciendo con ella sólo $19271 \mathrm{hl}$ de vino $(0.2 \%$ del total provincial). Además, este departamento no poseía un gran número de bodegas, las que sólo llegaban a un total de doce de las 1217 que existían en la provincia, y se trataba de bodegas pequeñas, con una capacidad de vasija de $34687 \mathrm{hl}$, lo que también significaba sólo $0.2 \%$ de la provincia.

\section{PolíticAS DE INCENTIVO A LA PRODUCCIÓN}

Antes de referirnos a las medidas específicas de fomento aplicadas por el gobierno sobre la actividad vitivinícola para aumentar la producción, creemos oportuno realizar un breve comentario sobre las características

\footnotetext{
${ }^{38}$ Representaba 13\% de establecimientos, 13\% del personal ocupado y $9 \%$ de los ingresos sobre el total de la provincia. Ibid., pp. 300-301.

${ }^{39}$ Representaba $1.5 \%$ de los establecimientos de toda la provincia, $0.6 \%$ del personal ocupado y $0.3 \%$ de los ingresos percibidos. Ibid., p. 300 .

${ }^{40}$ En cuanto a la distribución de esos cultivos, 40\% del área se hallaba plantada con vid, 30\% con alfalfa y otro $30 \%$ con papas, tomates, frutas, cebollas, melones, sandías, etcétera.

${ }^{41}$ Guibourdenche, "San", 1956.
} 
generales de las políticas económicas peronistas y la articulación naciónprovincia en la elaboración y ejecución de las mismas, a fin de brindar un panorama general de las diferencias con la planificación de épocas anteriores y los criterios de conducción que guiaron al gobierno peronista en la provincia de Mendoza.

Primeramente, debe destacarse que las políticas dirigistas aplicadas por el Estado sobre la industria en la década de 1930, sólo fueron un conjunto de medidas con alguna coherencia interna en función de un objetivo inmediato. Los "planes", que surgieron en esta época como respuesta a una necesidad impuesta por los acontecimientos, presentaron ciertas deficiencias ya que plantearon objetivos muy generales, indefiniciones teóricas, descuidos en el análisis económico y en la utilización de las herramientas necesarias para alcanzar aquellos objetivos. ${ }^{42}$ Así, se ha señalado que en esta década no hubo, en general, una política consciente y coherente de fomento, ni de apoyo directo a la industria local. ${ }^{43} \mathrm{El}$ gobierno revolucionario de 1943 marcó el inicio de una nueva etapa de la actitud del Estado frente al sector industrial, estableciendo una serie de instrumentos que serían los antecedentes inmediatos de la política económica peronista. Según el informe del Consejo Nacional de Posguerra, esta debía estar basada en un plan estable y sistemático, con objetivos de corto y largo plazos vinculados entre sí, y se proponía llevar adelante una planificación coordinada, con un ordenamiento a ejecutarse paulatinamente y de realización total, con miras al porvenir económico del país. ${ }^{44}$ Con base en este informe, la Secretaría Técnica de la presidencia de la nación, con rango de Ministerio, delineó el Primer Plan Quinquenal, que determinaba la orientación económica del país para el periodo 1947-1951. Este plan definía, aunque en algunos casos de modo imperfecto, ${ }^{45}$ las áreas de intervención estatal, establecía las políticas a implementar y diseñaba las instituciones y los instrumentos necesarios para llevarlas a cabo, impulsando un modelo de planificación que apuntaba a otorgarle un papel importante a la centralización de las políticas económicas y sociales.

${ }^{42}$ Jáuregui, "Planificación”, 2005, p. 16.

${ }^{43}$ Dorfman, Cincuenta, 1983, p. 531, y Tella y Zymelman, Etapas, 1967, pp. 435-436.

${ }^{44}$ Vicepresidencia, "Documentos", 1980, pp. 117-120.

${ }^{45}$ Debido a las falencias en los datos estadísticos, la falta de censos y, en definitiva, el desconocimiento de la realidad. Al momento de elaborar el plan, la Secretaría Técnica de la Nación se convirtió en el espacio de convergencia de actores y proyectos sectoriales, solicitando a los ministerios y organismos informes que especificaran acciones y proyectos factibles en marcha, en vías de ejecución o futuros, con el objetivo de organizarlos en un plan integral y coherente. Sin embargo, se produjo una situación dispar, ya que algunas áreas enviaron un conjunto "deshilvanado" de proyectos. En síntesis, la falta de información para un buen diagnóstico, la debilidad institucional, las capacidades desiguales de las dependencias y de los agentes del Estado, así como los conflictos políticos internos, obstaculizaron la racionalidad técnica que se pretendió imprimir, en Berrotarán, "Planificación", 2004, pp. 27-35. 
En relación con esto último y con base en investigaciones anteriores referidas a la elaboración de determinadas políticas sociales (educación y salud) y económicas, ${ }^{46}$ podemos afirmar que, en la práctica, el gobierno de la provincia respondió a las directivas y principios emanados desde la esfera nacional, es decir, existió una centralización de las decisiones en torno a los rumbos a seguir en Mendoza. Durante la gubernatura de Faustino Picallo (1947-1949), proveniente de las filas de la Unión Cívica Radical Junta Renovadora, ${ }^{47}$ las relaciones con el gobierno nacional fueron tranquilas, no se evidenciaron conflictos y cumplió su labor conforme a los principios y directivas de aquel nivel de gobierno. Cuando el peronismo mendocino fue cambiando de manos y pasó a gobernar la provincia un militar como fue Blas Brisoli (1949-1952), las relaciones con el presidente de la nación se afianzaron aún más y la injerencia del poder ejecutivo nacional sobre el provincial fue más notoria. ${ }^{48}$ Esta influencia se vio reflejada, por ejemplo, en la Constitución provincial sancionada en 1949, en la elaboración de los planes provinciales, en el sistema sanitario provincial, en el objetivo y destino de la política crediticia, en la fijación de los precios máximos, etc. La candidatura de este funcionario, al igual que la de los gobernadores de todas las provincias, fue designada por el Consejo Superior del Partido Peronista para presidir la fórmula gubernativa. Si esto suponía una estrecha relación con el presidente de la nación, lo era aún más el hecho de haber sido Brisoli el secretario privado de Perón. ${ }^{49}$ Estos factores permiten suponer su indudable lealtad hacia el líder a la hora de diseñar las políticas públicas. Además, “dado el verticalismo del gobierno, los gobernadores obedecían ciegamente las directivas del gobierno central y desviaban las posibilidades de gobernar directamente la provincia obedeciendo totalmente las directivas nacionales en lo económico, político y social" ${ }^{50} \mathrm{Du}$ rante la gubernatura de Carlos Evans (1952-1955), el "verticalismo" en la elaboración de las políticas públicas continuó. Al comenzar su administración, fue sancionado el Segundo Plan Quinquenal Provincial en adhesión al nacional, ${ }^{51}$ y si bien era "voluntaria" la adhesión al mismo, ella era una condición básica para obtener los recursos de la nación para la puesta en práctica del plan de obras provinciales. ${ }^{52}$ Dicha adhesión implicaba, además, la adopción por parte de la provincia de los lineamientos generales

${ }^{46}$ Véase Hirschegger, "Políticas", 2009.

${ }^{47}$ Mejor conocida como, Unión Cívica Radical Junta Renovadora, fuerza que brindó el apoyo a Perón.

48 Álvarez, "Mendoza”, 1993, pp. 176-177.

${ }^{49}$ Gonzáles, Historia, 1996, pp. 188 y 196.

${ }^{50}$ Álvarez, "Mendoza”, 1993, pp. 176-177.

${ }^{51}$ Presidencia, Segundo, 1953, pp. 319 y 357.

${ }^{52}$ A este requisito se le sumó, según Bacolla, la pertenencia partidaria de los gobernadores, véase Bacolla, "Política", 2003, p. 147. 
impuestos desde el gobierno nacional. ${ }^{53}$ Se visualiza entonces y a lo largo del peronismo en Mendoza, la intervención o imposición del gobierno nacional en el diseño de la política provincial.

Como veremos a continuación, además del establecimiento de los precios máximos (medida derogada en 1954), el gobierno nacional y provincial aplicó un conjunto de políticas permanentes destinadas a aumentar la producción de vino, la cual había descendido en toda la provincia dada las pérdidas de uva causadas por los fenómenos climáticos (heladas y granizo). El hecho de que la disminución de vino siguiera la misma tendencia que la de uva, sobre todo a partir de la cosecha 1948-1949, indica una incidencia hegemónica de estos fenómenos naturales sobre los descensos mencionados (véase gráfica 2).

Por lo tanto, el problema de la escasez en ciertos años se asociaba más a factores naturales que al contexto económico imperante. Debe destacarse que en los descensos producidos en el periodo señalado, influyó considerablemente el comportamiento de la industria del municipio de San Rafael (véase gráfica 3), representando casi 10\% de la producción total. Si bien no poseemos datos sobre el comportamiento de la producción de Lavalle en el periodo 1947-1950, conjeturamos que, en el caso de haberse producido algún tipo de contingencia climática en esos años, la repercusión sobre el total provincial no debe haber sido significativa, ya que hacia 1947 su producción sólo representaba 2\%. La gráfica 4 muestra la evolución que tuvo la producción en Lavalle entre 1951 y 1955, tema que será abordado más adelante.

Las medidas aplicadas, que no se limitaron sólo a resolver cuestiones vinculadas con los fenómenos climáticos, significaron, además, beneficios para los distintos subsectores de la industria. Entre estas podemos mencionar las políticas de riego, el otorgamiento de créditos, el seguro agrícola y el fomento del sistema cooperativo. ${ }^{54} \mathrm{Tal}$ como se hallaba plasmado en los dos planes quinquenales nacionales, estos serían los instrumentos a través de los cuales tanto el Estado nacional como la provincia fomentarían el crecimiento de la actividad.

En aquellos años en los que no se produjeron fenómenos climáticos, o estos no fueron significativos, la producción de uva tanto en la provincia

\footnotetext{
${ }^{53} \mathrm{Al}$ respecto Carlos Evans sostendría que: “[e]l segundo Plan Quinquenal del general Perón nos dará en breve los proyectos definitivos que habrán de realizarse en la provincia de Mendoza. Oportunamente, de acuerdo con esas directivas, consideraré con vuestra honorabilidad las exigencias prácticas de todas y cada una de las iniciativas que correspondan a la colaboración provincial", en Gobierno, Mensaje, 1952, p. 27.

${ }^{54}$ Para las políticas destinadas a resolver problemas de tipo fitosanitario como la filoxera y que tuvieron cierta incidencia en el comportamiento de la producción, véase Hirschegger, "Agroindustrias", 2010.
} 


\section{GRÁFICA 2. UVA VINIFICADA Y VINO PRODUCIDO, MENDOZA, 1947-1955}

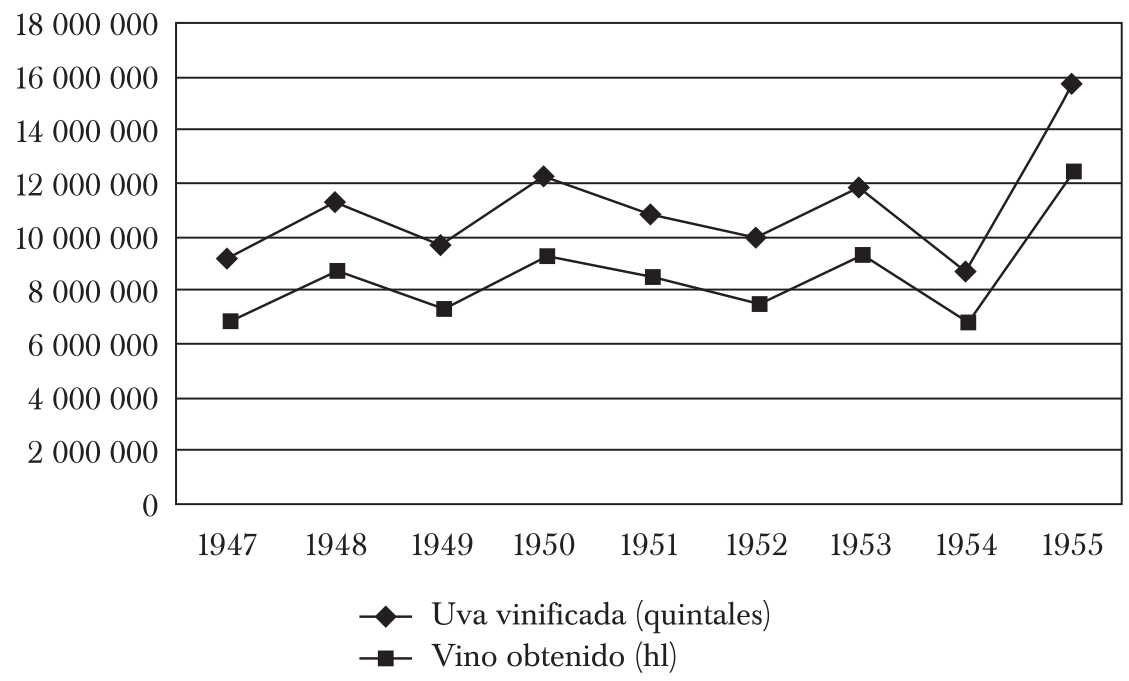

Fuente: elaboración propia con base en datos de Anuario, 1954 y 1956.

en general como en San Rafael en particular mostró una recuperación o un crecimiento en relación con los años inmediatamente anteriores (véanse gráficas 2 y 3), siguiendo la misma tendencia la producción de vino. $\mathrm{Si}$ bien podemos pensar que durante el gobierno peronista los momentos de crecimiento sólo estuvieron supeditados a la ausencia de heladas o granizadas, sostenemos que el comportamiento positivo de la producción también estuvo impulsado por las políticas públicas destinadas a fomentar la actividad, tanto primaria como industrial.

Aumento de la superficie cultivada. Políticas de irrigación:

reformas en el régimen de aguas y planes de obras

"Debemos extender la plantación de viña racionalmente". Según el ministro de Economía de la provincia, José de Paolis, ${ }^{55}$ este era el primer punto sobre el que debían centrarse las políticas del gobierno. p. 3.

55 "Debemos extender la plantación de viña racionalmente", Los Andes, 10 de abril de 1947, 


\section{GRÁFICA 3. UVA VINIFICADA Y VINO PRODUCIDO, SAN RAFAEL, 1947-1955}

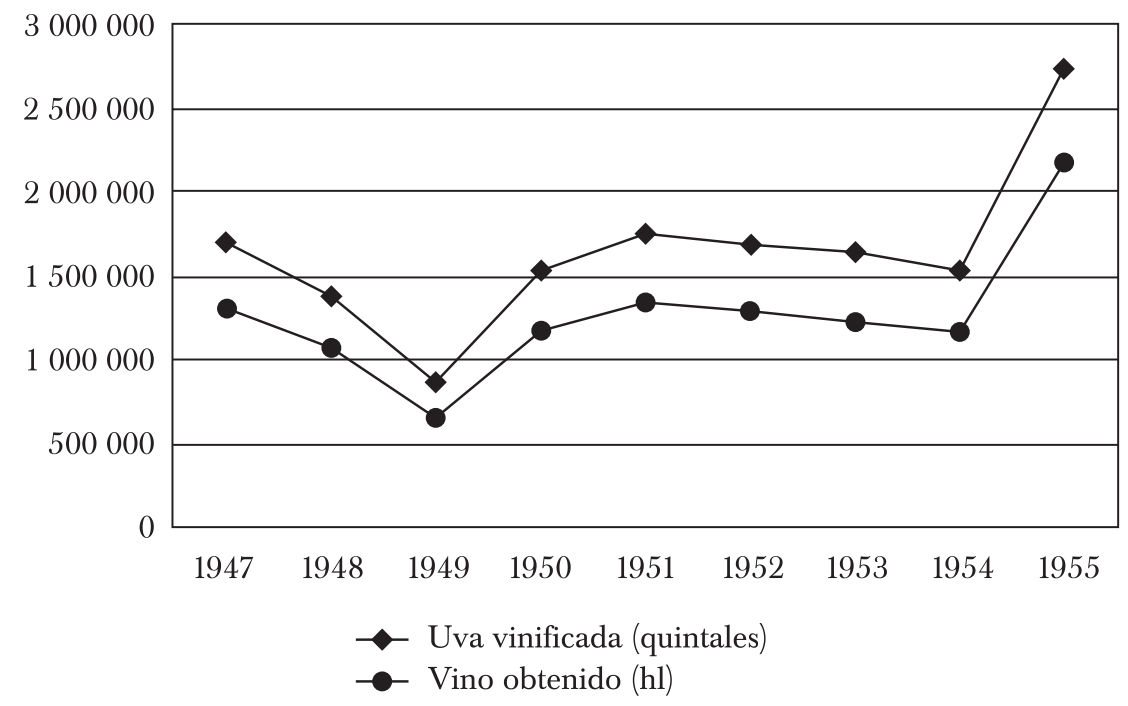

Fuentes: elaboración propia con base en Anuario, 1952, pp. 54-65, y 1954, pp. 58-59 y 63; Gobierno, Boletín, 1955, pp. 7 y 9; “Dirección”, 1946, pp. 18 y 91, y Banco, Vigésimo, 1954, p. 76.

En la gráfica 5 se observa un aumento progresivo de las hectáreas cultivadas en el periodo 1947-1952 en relación con 1943-1947. Si bien el ascenso de la superficie en los primeros años del gobierno respondió a la derogación, en 1944, de los decretos que prohibían la plantación de viñedos, consideramos que en el ritmo más acentuado que adquirió la extensión de las hectáreas a fines de la década de 1940 en adelante, en San Rafael y más lento en Lavalle, incidió la política de irrigación que tanto el gobierno de la provincia como el de la nación llevó a cabo durante el peronismo. Aunque no debemos obviar el otorgamiento de préstamos para la plantación de nuevas viñas por parte del sistema bancario oficial, tal como veremos luego.

En las provincias del centro-oeste, a diferencia de las regiones del litoral y centro de la República Argentina, los cultivos dependen del riego artificial. En Mendoza, el riego derivaba de las aguas de los cuatro ríos principales: Mendoza, Tunuyán, Diamante y Atuel. Sin embargo, tanto desde el Estado como de otros sectores - por ejemplo el científico-, se 
GRÁFICA 4. UVA VINIFICADA Y VINO PRODUCIDO, LAVALLE, 1947-1955

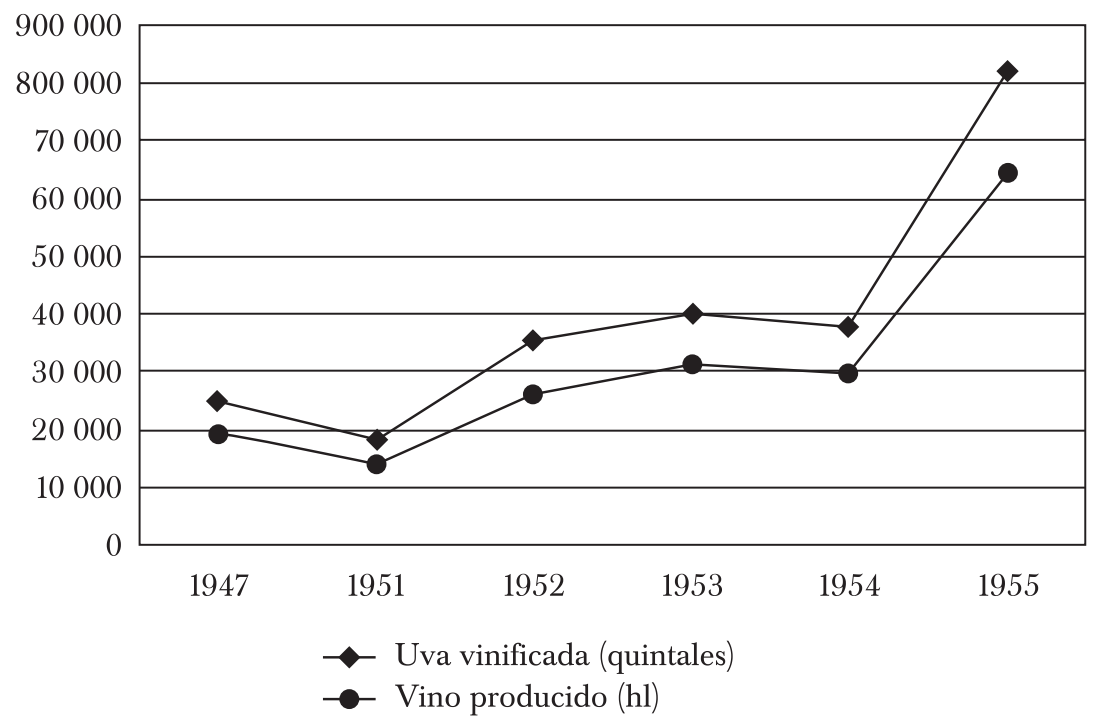

Fuentes: Anuario, 1952, pp. 54-65, y 1954, pp. 58-59 y 63.

reconocía la escasez de agua para riego. ${ }^{56} \mathrm{Si}$ bien la atención del gobierno estuvo centrada en aumentar el área cultivada en general, el interés preferencial se dirigió al riego de aquellas propiedades cultivadas con vid. ${ }^{57}$

En la memoria del Departamento General de Irrigación de 1946 se destaca que el problema fundamental de la escasez de agua era la disminución de los caudales de los ríos, ${ }^{58}$ pero también la inadecuada distribución del agua debido a la falta de una política racional en materia de riego. ${ }^{59}$ Como respuesta a esta situación, el gobierno provincial desarrolló una intensa actividad legislativa. Si bien anteriormente hemos mencionado que las medidas a seguir eran pautadas desde los niveles superiores de gobierno, en algunos casos fueron resultado también de la interacción entre las autoridades provinciales y los sectores más afectados -los regantes-

${ }^{56}$ Riveros, “Disminución”, 1946, p. 325.

${ }^{57}$ Hacia 1947 representaban 40\% de la superficie cultivada de la provincia, en Cremaschi, "Problemas", 1947, p. 403.

${ }^{58}$ Departamento, Memoria, 1949, pp. 103-115.

${ }^{59}$ Ibid., p. 162. 
GRÁFICA 5. SUPERFICIE CULTIVADA CON VID (HA), 1943-1960

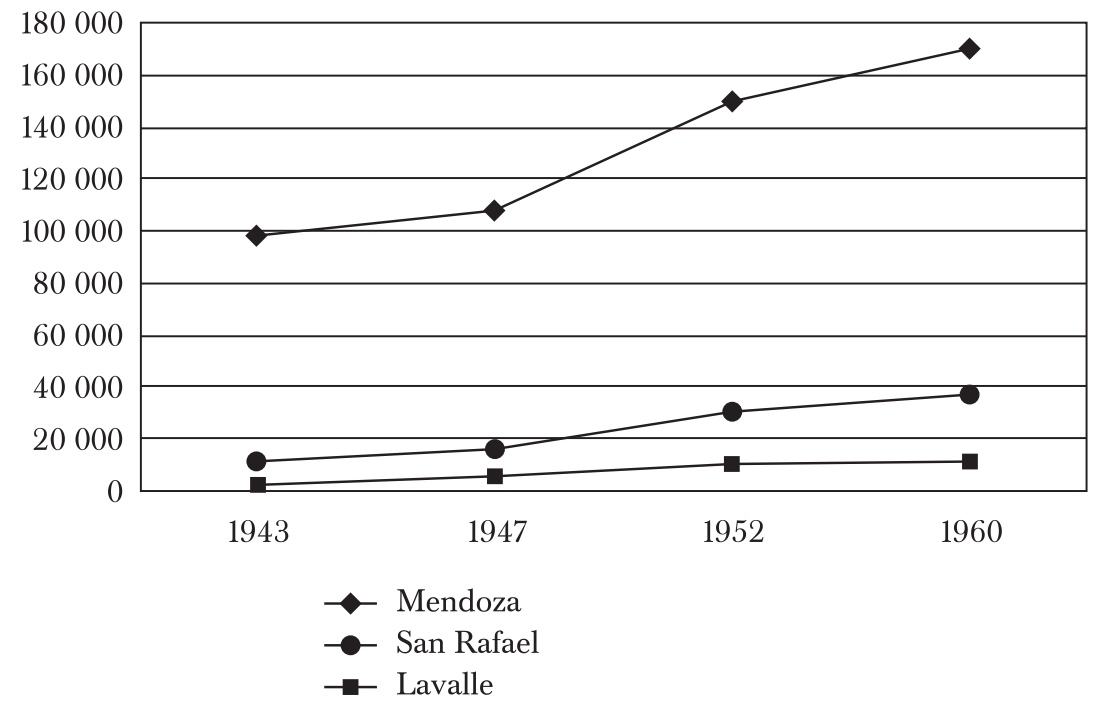

Fuentes: elaboración propia con base en Censo, 1949, p. 9, y 1962, p. 27.

producida en las diferentes reuniones y asambleas convocadas, tal como se desprende de las memorias del Departamento General de Irrigación. ${ }^{60}$ Así, entre otras cosas, se procedió a la reestructuración del citado organismo, la racionalización administrativa, el dictado de medidas destinadas a perfeccionar los procedimientos en el manejo del riego ${ }^{61}$ y a la conformación de planes de obras destinados a mejorar el sistema de irrigación. ${ }^{62}$

En 1947 fue sancionada la Ley especial núm. 1676 de elección de autoridades de agua, por la cual los inspectores y delegados de cauce serían

${ }^{60} \mathrm{Si}$ bien se pensó desde un primer momento realizar un congreso nacional de riego, no tenemos registros de su concreción. Los puntos principales que se tratarían eran: relacionar los problemas regionales para adoptar un plan de iniciativas generales, repartir el peso de las financiaciones, encarar la legislación nacional del agua con un reconocimiento expreso inviolable de los patrimonios provinciales, conocer detenidamente todas las iniciativas públicas y privadas del riego a fin de orientar con el mejor aporte la obra fundamental del gobierno. Departamento, $\mathrm{Me}^{-}$ moria, 1949, p. 169.

${ }^{61}$ De modo de restringir el abuso de las concesiones y limitar la arbitrariedad de las autoridades encargadas de distribuir el servicio.

${ }^{62}$ Departamento, Memoria, 1950, pp. 328-329. 
elegidos por los propietarios regantes a simple mayoría de votos. ${ }^{63}$ Por otra parte, la Constitución de Mendoza de 1949 creó un apartado dedicado al régimen de aguas que, comparada con la anterior (que databa de 1916), ampliaba las disposiciones referentes al sistema, disponiendo sobre usos, aprovechamiento, distribución, administración y policía de las aguas públicas. Esto último, en contra de una práctica muy común como eran los cultivos clandestinos, es decir, aquellos que se realizan en terrenos sin derecho de agua acordado ${ }^{64}$ situación motivada por el fraccionamiento ficticio de los inmuebles y de los derechos de agua. ${ }^{65}$

Sobre el problema de los cultivos clandestinos nos limitaremos a señalar que la Constitución de 1949 dispuso que aquellos que se efectuaran después de su publicación, sería eliminados y penados, y sus autores, sometidos a la acción de la justicia ordinaria. Por otra parte, la Ley provincial núm. 1920 de 1950 -y su modificatoria núm. 2 032-, ${ }^{66}$ legisló sobre cultivos clandestinos $^{67}$ y su puesta en práctica se vio reflejada en las aproximadamente 9500 ha denunciadas en la oficina de cultivos clandestinos en 1952, perteneciendo su mayoría a la plantación de viñas $(50 \%)$ y frutales $(30 \%)$, a los que le seguían forestales y chacras. ${ }^{68}$

${ }^{63} \mathrm{Si}$ bien se verifican ciertas modificaciones y agregados, en algunos puntos se evidencia cierta continuidad respecto a la vieja ley de aguas, ya que se continúa estableciendo la cantidad de votos por propietario según la cantidad de hectáreas y no hay aclaraciones sobre la naturaleza de los terrenos. Ley núm. 1 676, en Boletín, 1947.

${ }^{64}$ Hay propietarios que poseen un inmueble de 50 ha, de las cuales sólo 30 tienen derecho de agua registrado. Sin embargo, riegan la totalidad de las mismas. Se denomina, en este caso, como cultivo clandestino, al excedente de 20 ha sin derecho de riego que el propietario cultiva con agua que tiene asignada sólo para 30 de ellas, en Marianetti, Problemas, 1947, p. 206.

${ }^{65}$ Las sanciones aplicadas fueron multas y en algunos casos la destrucción de los cultivos. Durante la intervención de Aristóbulo Vargas Belmonte (1943-1946) se dictó en Mendoza el Decreto-Acuerdo núm. 862 de 1945 reglamentando la cuestión de los cultivos clandestinos, que establecía que todos aquellos propietarios que tuvieran esta clase de cultivos debían denunciarlos dentro de un plazo determinado, presentar planos estableciendo la extensión de dichos cultivos, señalar las fracciones cultivadas y pagar un determinado derecho, en ibid.

${ }^{66}$ Fijaba nuevos plazos para el denuncio de cultivos clandestinos y complementa la Ley núm. 1920 en Boletín, 1952.

${ }^{67}$ Establecía los casos en que los cultivos serían considerados clandestinos y prohibía el suministro de aguas públicas a los inmuebles sin derecho de riego. Además, todas las autoridades de irrigación debían tomar medidas para la utilización y distribución equitativa y proporcional del agua a favor de los regantes legítimos. También se establecían beneficios (derecho eventual de riego de aguas vivas o de desagües) para regularizar la situación de los cultivos clandestinos o ilegítimos de carácter permanente, pero limitados a las superficies reales cultivadas. Dichos cultivos deberían constituir una mejora definitiva incorporada al predio y una riqueza económica ya acumulada; estar en buen estado y distribuidos en forma normal de plantación y no por hileras o grupos aislados; y poseer un mínimo de plantas por hectárea, con cierta antigüedad y radicación en el inmueble. Esta disposición se aplicaba para las plantaciones en montes forestales de especies arbóreas, montes de árboles frutales, y viñas que a la fecha del denuncio estuviesen plantadas en forma uniforme. Ley núm. 1 920, en Boletín, 1950.

${ }^{68}$ Es decir, el caso más común era el de los cultivos permanentes, regados por los ríos. En total sumaron 1487 los expedientes iniciados por oficina de cultivos clandestinos, véase Departamento, Memoria, 1954, pp. 72-73. 
Continuando con la legislación provincial de aguas, bajo el régimen de la Ley núm. 1420 de 1941, ${ }^{69}$ el Departamento General de Irrigación, con aprobación del poder ejecutivo, elaboró y realizó un plan de obras menores ${ }^{70}$ Por esta ley se dejaba establecido además, la formación de un fondo permanente para financiar las grandes obras proyectadas directamente por aquella rama del Estado (diques distribuidores y de embalse, grandes canales, etc.). ${ }^{71}$ Sin embargo, según el discurso del gobernador, en la aplicación de esta ley no se cumplía el principio de la igualdad de todos los contribuyentes, ya que mientras todos aportaban por igual a la formación del fondo destinado a las obras, estas eran proyectadas con "criterio localista", beneficiando a ciertas zonas en detrimento de otras. Esta situación fue corregida entonces por la Ley núm. 1744 del año 1948, que dividía a la provincia en zonas correspondientes a sus cuatro ríos (Mendoza, Tunuyán, Diamante, Atuel) y sus respectivas áreas de influencia. Dentro de cada zona, los fondos se distribuirían equitativamente y conforme a los recursos existentes en cada una de ellas, no pudiendo emplearse la totalidad de ellos en una sola obra, sino que debían beneficiar los distintos tramos de ríos, cauces o sistema de riego. ${ }^{72}$

En 1952 se introdujeron nuevas modificaciones con la Ley provincial núm. 1 981, la que además de aumentar los recursos que constituirían el fondo mencionado, financiaba obras de menor envergadura (desagües, saneamiento, sistematización y encauzamiento de sobrantes, perforación para obtener aguas subterráneas, etcétera). ${ }^{73}$

Una de las causas por los que casi la mitad de la superficie con derecho de riego no recibía agua, tanto en San Rafael como en Lavalle, era la falta de obras y las pérdidas por infiltración en el lecho de la gran mayoría de los cauces. Estos problemas existían en ambos departamentos, y se reflejaban a través de las denuncias de los regantes y autoridades del agua. En San Rafael, muchos son los reclamos que pueden mencionarse, ${ }^{74}$ pero

${ }^{69}$ Boletín, 1941. federal.

${ }^{70}$ Algunas de las cuales ya habían sido iniciadas durante el gobierno de la intervención

${ }^{71}$ Constitución, 1916.

${ }^{72}$ Véanse Boletín, 1948, pp. 2542-2543, y Gobierno, Mensaje, 1949, p. 63.

${ }^{73}$ Quedaban excluidas de los beneficios del fondo aquellas obras mayores y las previstas por las autoridades de cauces de riego o desagües en sus respectivos presupuestos y demás obras autorizadas por leyes especiales. Ley núm. 1 981, en Boletín, 1951. Si bien estos trabajos se financiarían con el fondo establecido por las leyes, existieron otras fuentes de financiamiento principalmente para obras mayores, como fueron los presupuestos provinciales, leyes especiales y decretos del poder ejecutivo, en Departamento, Memoria, 1949, pp. 9-14.

${ }^{74}$ Según las Memorias de 1946 del Departamento General de Irrigación, el río Atuel, que según el último censo agrícola regaba aproximadamente 70000 ha, se caracterizó por su extraordinaria escasez de agua, sobre todo entre septiembre y diciembre de ese año, en los que los caudales fueron los más bajos de los últimos diez años, véase Departamento, Memoria, 1949. En noviembre 
el caso de los agricultores de la colonia San Pedro del Atuel es de singular importancia, ya que se trató de una demanda dirigida directamente al presidente de la nación pidiendo soluciones al respecto. ${ }^{75}$ Por otra parte, en una nota enviada por un dirigente gremial del sector gastronómico, se pidió, entre otras cosas, la realización de obras para aumentar las áreas de riego ${ }^{76}$ Las solicitudes también recayeron sobre organismos provinciales, principalmente sobre el Departamento General de Irrigación. Tal es el caso de los regantes de los distritos 25 de Mayo, ${ }^{77}$ Goudge, Monte Comán ${ }^{78}$ y Real del Padre. ${ }^{79}$

En cuanto a Lavalle, un caso importante que podemos citar fue el envío de una nota del intendente municipal -Alberto Severino- al presidente, detallando las obras que necesitaba la comuna, entre ellas, las destinadas a dotar de agua para irrigar una extensa zona del municipio. ${ }^{80}$ También los regantes y entidades representativas del departamento expu-

de 1947 hubo una disminución notable, ocho metros cúbicos por segundo de un día para otro. Véase "Ha disminuido el caudal de agua del río Atuel", Los Andes, 27 de noviembre de 1947, p. 7. Graves perjuicios causaba el mal estado del desagüe general de Cañada Seca, principalmente problemas de limpieza, afectando la tierra destinada a la siembra de cultivos anuales, viñedos y frutales. Véase "Grandes perjuicios causa el desagüe general de Cañada Seca", Los Andes, 16 de noviembre de 1949, p. 6. Según los inspectores de cauces de riego de los distritos de Villa Atuel y Real del Padre, desde la segunda quincena de marzo de 1949 se venía reduciendo en forma progresiva la dotación de agua de los canales de la zona, en forma tal que escasamente alcanzaba para uso humano. Agregaron que el embalse El Nihuil suministraba 19 metros cúbicos por segundo, caudal que consideraban insuficiente, pues sólo permitía entregar una reducida dotación a los canales. Sobre esto, expresaron que la amplia red de canales que irrigaba la zona de cultivos que abarcan los distritos mencionados, conducen desde el 15 de marzo apenas un hilo de agua, contrastando ello con la importancia incuestionable que tiene la región dentro del área de cultivos de la zona sur de la provincia. Este dique tenía en esos momentos una reserva de agua de 40600 hectómetros cúbicos, considerando por ello, que podía aumentarse la dotación que se suministraba. Véase "Se provee de escaso caudal al río Atuel desde el 15 de marzo", Los Andes, 14 de abril de 1949 , p. 4.

75 "La disminución del caudal del río Atuel causa alarma", Los Andes, 9 de enero de 1948, p. 5.

76 "Iniciativas para el Segundo Plan Quinquenal", en Archivo General de la Nación (en adelante AGN), Secretaría Técnica, leg. 17 502, 1952.

${ }^{77}$ Departamento, Memoria, 1949, pp. 178-179.

${ }^{78}$ En el distrito de Goudge los regantes y autoridades del canal Matriz Monte Comán, derivado del río Diamante, solicitaron la intervención de la Subdelegación Diamante a fin de regularizar la distribución del agua. Según lo expresan, "hemos constatado [...] que nuestro canal tiene debajo de la dotación normal, mientras otros, tienen por arriba de la correspondiente", en "Regantes de Goudge hacen una grave denuncia", El Comercio, 9 de enero de 1947, p. 4. En el distrito de Monte Comán, la escasez de agua para el cultivo produjo la disminución de las cosechas considerablemente. Según los testimonios de los agricultores, quienes poseían fracciones de diez hectáreas sólo lograrían una producción de tres o cuatro, pues el agua entregada no permitió el riego de un espacio mayor. Por el contrario, dicen los agricultores, "otras zonas irrigadas por el Diamante han tenido caudales que han abastecido a la totalidad de sus inmuebles", en "Alarmante escasez de agua hay en la zona de cultivo”, El Comercio, 18 de febrero de 1950, p. 6.

${ }^{79}$ Departamento, Memoria, 1954, p. 49.

80 "Iniciativas para el Segundo Plan Quinquenal”, en AGN, Secretaría Técnica, carpeta 27, leg. 11186. 
sieron ante las autoridades provinciales los principales problemas de riego y solicitaron la construcción de obras. ${ }^{81}$

Respecto a las políticas tendentes a solucionar estos problemas, San Rafael se encontraba entre los que mayor cantidad de obras recibiría. En realidad, entre las aproximadamente 150 obras a realizar por el gobierno de la provincia (planificada, en estudio y licitadas), la mayoría de ellas fueron destinadas a cuatro departamentos, ocupando San Rafael el primer lugar, mientras que Lavalle el tercero. En el departamento del Sur, las obras en los ríos Diamante y Atuel incluyeron la construcción de diques derivadores, ${ }^{82}$ canales marginales, obras de desagüe, obras de defensa, sistematización de tomas, cámaras desarenadoras, pozos para riego, etc. ${ }^{83}$ No debemos dejar de destacar además la construcción del dique El Nihuil por el gobierno de la nación. ${ }^{84}$

En general, la importancia de la política de obras de riego llevada a cabo por el gobierno provincial puede verse reflejada en el hecho de que en el trienio 1949-1951, 70\% de las obras proyectadas habían sido terminadas y entre ellas se destacan la construcción de diques derivadores, impermeabilización de cauces, construcción y arreglo de tomas, perforaciones de pozos, mantenimiento, revestimiento y construcción de canales, etc. ${ }^{85}$ Esto significa que, siguiendo los planes quinquenales nacionales, los gobiernos provinciales crearon infraestructura destinada a resolver tal problema ${ }^{86}$ Así, la construcción, reparación y conservación de obras de riego fue una política permanente del gobierno de la provincia de Mendoza, instrumentada a través de los Planes Trienales de Obras y Servicios Públicos (1947-1951) ${ }^{87}$ y el Segundo Plan Quinquenal Provincial (1952-1955).

Como hemos visto, durante el gobierno peronista hubo un avance importante en materia de irrigación, no sólo por el perfeccionamiento de su legislación (orientada hacia objetivos más específicos y determinando las zonas de incidencia), sino también por la concreción de un vasto plan de obras de riego, lo que redundó en un aumento de la superficie irrigada y del área cultivada tanto en la provincia en su conjunto como en los departamentos estudiados. Esto es prueba de una exitosa aplicación -aun-

${ }^{81}$ Departamento, Memoria, 1949, p. 75.

${ }^{82}$ Departamento, Memoria, 1950, p. 191.

${ }^{83}$ Ley núm. 1 610, en Boletín, 1946; Gobierno, Mensaje, 1948, 1949 y 1950; Oficina, Perón, 1952, pp. 27-123, y Gobierno, Mensaje, 1953, pp. 51-55.

${ }^{84}$ Terminada en 1948, en Gobierno, Agua, 1952, p. 155.

${ }^{85}$ Ibid., pp. 49-51, y Departamento, Memoria, 1949, 1950, 1951 y 1954. Respecto a los años siguientes no se posee información que permita sacar un porcentaje de las obras concretadas.

${ }^{86}$ Presidencia, Plan, 1947, pp. 332-333.

${ }^{87}$ Ley núm. 1565 de 1946; Ley núm. 1617 de 1947; modificatoria de la Ley 1795 de 1949; Ley núm. 1900 de 1950, en Boletín, 1946, 1947, 1949 y 1950, respectivamente. 
que fuera de modo parcial- de las políticas de riego planificadas por el gobierno.

\section{La política crediticia: el Banco de la Nación Argentina y el Banco de Mendoza}

Otro de los instrumentos utilizados para estimular las actividades agroindustriales fue el otorgamiento de préstamos. La reforma financiera realizada en el año 1946 fue el eje de una renovada política crediticia a favor de la producción en general, y de la industria en particular, que se concretó a través del Banco de la Nación Argentina,${ }^{88}$ y del Banco de Crédito Industrial Argentino -encargado de otorgar créditos a la pequeña y mediana industria- ambos representantes del gobierno de la nación. El gobierno de la provincia actuó por intermedio del Banco de Mendoza. En el presente apartado nos referiremos brevemente a cada uno de ellos.

En relación con el Banco de la Nación Argentina y en virtud del Decreto-Ley núm. 14959 de 1946, el crédito al sector rural otorgado creció en importancia en el conjunto de operaciones de la entidad. Según las memorias del banco, los préstamos a los productores del campo representaron 39\% del total de la cartera comercial. Hacia 1949, la acción crediticia del gobierno de la nación destinada al agro se intensificó, produciéndose, por un lado, la adaptación de las reglamentaciones de préstamos especiales y de fomento en función de la evolución económica y las características regionales de las distintas zonas agrícolas, y por otro, la implantación de nuevos créditos y servicios. La contribución del Banco de la Nación Argentina a la campaña antiinflacionaria trazada por el poder ejecutivo $-\mathrm{y}$ aplicada por el Banco Central- llevó al reordenamiento de la distribución del crédito, negado a las actividades especulativas y facilitado no sólo a los productores de bienes exportables (destinados a la obtención de divisas), sino también de bienes básicos de consumo interno. De acuerdo con ello, se ampliaron los créditos a los productores rurales e industriales, dedicados al acondicionamiento, conservación o transformación de productos agrarios en las regiones productoras. ${ }^{89}$

Respecto a la actividad vitivinícola, uno de los objetivos del banco fue recomponer el sector a través del aumento de la producción ${ }^{90}$ para lo cual se delineó un conjunto de normas orientadas a beneficiar a los productores

\footnotetext{
${ }^{88}$ Los rasgos esenciales de la política crediticia instrumentada por el Estado en relación con el fomento industrial han sido desarrollados por Rougier, Politica, 2001, y Girbal-Blacha, Mitos, 2003.

${ }^{89}$ Banco, Memorias, 1950, p. 14.

${ }^{90}$ Ibid., Banco, Memorias, 1949, pp. 125, 128-129; Banco, Memorias, 1951, pp. 61, y Banco, Memorias, 1953, pp. 162, 168, 179 .
} 
agrícolas e industriales. Fue así como a partir de nuevos estudios realizados por esta institución bancaria, se concedió préstamos para la plantación de nuevos viñedos, la ejecución de trabajos complementarios y la adquisición de materiales relacionados con esa clase de cultivos (preparación de la tierra, compra de postes, alambres, etc.). El monto de los créditos acordados por hectárea era de 5000 pesos y por firma de 50000 pesos, siempre que los viticultores fueran propietarios de la tierra y gozasen de los derechos definitivos de riego. También se prestaba hasta 1500 pesos a los propietarios para restaurar las plantaciones existentes de la misma especie. Los plazos de reintegro eran en cuotas anuales de $20 \%$, con un interés de $6 \%$ anual. ${ }^{91}$ Se otorgaban además mayores facilidades a los dueños de tierras que tuviesen intención de incorporarlas a las explotaciones vitícolas pero que no contaran con los medios para mejorar sus plantaciones. ${ }^{92}$

La ayuda bancaria también se hizo extensiva a la construcción de vasijas de conservación ${ }^{93}$ y al fomento del cooperativismo para solucionar el problema de los viñateros sin bodega. ${ }^{94}$ Algunos rasgos del cooperativismo durante el peronismo serán presentados más adelante.

En 1950, el Banco de la Nación Argentina acentuó su accionar destinado a aumentar y mejorar la producción agropecuaria. En particular, estableció el otorgamiento de créditos especiales para nuevas plantaciones de viñas, restauración de viñedos existentes, préstamos para la compra de uva, para la recolección de cosechas y para mejoras o ampliación de bodegas. ${ }^{95} \mathrm{Al}$ año siguiente, y con el objetivo de solventar las necesidades provenientes del aumento de los gastos de plantación y restauración de viñedos, el directorio del banco resolvió modificar su anterior reglamentación elevando los porcentajes de crédito a la ampliación de las plantaciones y reposición de viñedos y a sufragar los gastos de la vendimia, compra de uva y su elaboración, ${ }^{96}$ y con ello, beneficiar tanto al viñatero como al pequeño bodeguero. Por ejemplo, se elevó el monto para la ampliación de viñedos a 9000 pesos por hectárea, calculando que ello representaba

91 "Concederá el Banco de la Nación préstamos para las plantaciones de vid", El Comercio, San Rafael, Mendoza, 2 de agosto de 1949, p. 4.

${ }^{92}$ Resolución que respondía al petitorio formulado por los ocupantes de los lotes fiscales de la institución, que solicitaban autorización para plantar vides en áreas no superiores a 30\% de las tierras adjudicadas, véase "Ampliación del área plantada con vides", El Comercio, 4 de agosto de 1949 , p. 4.

${ }_{93}$ Lo cual permite la elaboración de vinos finos que requieren un periodo de añejamiento antes de librarse al mercado.

94 “Ayuda bancaria a la economía de Cuyo", Los Andes, 1 de julio de 1949, p. 4.

${ }^{95}$ Resultado de un acuerdo entre el gobierno de la provincia de Mendoza y la institución bancaria. Antes de este, el directorio del banco visitó las provincias de Mendoza y San Juan para conocer los problemas locales. Véase "Fija nuevas medidas crediticias el Banco de la Nación Argentina", Los Andes, 20 de agosto de 1951, p. 4.

96 "Préstamos especiales a los vitivinicultores", Los Andes, 12 de marzo de 1951, p. 4. 
$80 \%$ de los gastos de mano de obra y de material. ${ }^{97}$ Las operaciones debían ajustarse a un plazo de cinco años con un interés de 5\% anual. El plazo para reintegrar el préstamo era de cuatro años con pagos de 15, 30 y $40 \%$ anual. ${ }^{98}$ Vemos aquí, entonces, mayores beneficios para los destinatarios de los préstamos, debido al aumento de los montos por hectárea de aproximadamente $80 \%$ y una tasa de interés más baja. Es representativa la importante acción desarrollada por este banco oficial entre 1948 y 1954, ${ }^{99}$ con un crecimiento significativo del número de operaciones destinadas a la industria vitivinícola, que llegó a 150\% tanto entre 1948-1950 como entre 1952-1954 (véase cuadro 2).

El hecho de que muchos productores agroindustriales (trasladistas) dejaran de elaborar, ${ }^{100}$ sugiere que el mayor porcentaje fueron dirigidas a los grandes establecimientos y, en este sentido, podemos tomar a Girbal-Blacha cuando sostiene que fueron las grandes bodegas "las mayores beneficiarias de los créditos otorgados por el Banco de la Nación Argentina". ${ }^{101}$ Esto puede corroborarse observando el número de explotaciones agropecuarias con viñedos en la provincia entre 1947 y 1960, cuyo aumento se produjo en mayor medida para las grandes propiedades (55\%), es decir, aquellas pertenecientes a los viñateros-bodegueros que integraban el ciclo completo de la producción e industrialización. ${ }^{102}$ Esto nos lleva a inferir entonces que este sector fue el más beneficiado por el banco, no sólo para la adquisición de nuevas tierras, sino también para gastos de todo el proceso productivo (instalaciones, herramientas, etc.) y, como ya hemos señalado, para la mejora física de las bodegas. Con este fin también fue orientada la acción del Banco Industrial de la República Argentina, que apoyó a la industria vitivinícola a través de créditos para ampliar la capacidad de vasija vinaria en las provincias de San Juan y Mendoza. Un ejemplo de esta acción lo constituyó el aumento de 30\% de las operaciones entre 1954 y $1955 .^{103}$

La ampliación de bodegas fue concretada, ya que entre 1951 y 1954 se evidencia un aumento de la capacidad de vasija frente a una dismi-

97 "Nuevos créditos para viñedos", Los Andes, 18 de junio de 1951, p. 4.

98 "Préstamos para el fomento vitícola", Los Andes, 27 de julio de 1951, p. 3.

${ }_{99}$ Debemos aclarar que se trata de préstamos destinados no sólo al sector vitivinícola de la provincia de Mendoza, sino de todo el país, ya que esta es la clasificación que brindan las memorias de la entidad.

${ }^{100}$ Como ya mencionamos en el presente artículo, ante los precios fijados por el Estado les resultaba más redituable vender su uva a los grandes establecimientos que producir su propio vino.

${ }^{101}$ Entre ellas, Giol S. A., El Globo S. A., Grisú S. A., La Superiora S. A., Escorihuela S. A., Benegas Hnos. y Cía., en Girbal-Blacha, Mitos, 2003, pp. 155-156.

${ }^{102}$ Según el Censo agropecuario de 1960, en esta categoría estaban aquellos propietarios de viñas de más de 50 ha, en Censo, 1962, p. 25.

${ }^{103}$ Banco Industrial, 1956, pp. 19 y 67. 
Am. Lat. Hist. Econ., año 19, núm. 3, septiembre-diciembre, 2012, pp. 57-97

\section{CUADRO 2. PRÉSTAMOS OTORGADOS A LA PROVINCIA DE MENDOZA}

\begin{tabular}{lc}
\hline Años & Número de operaciones \\
& \\
1948 & 572 \\
1950 & 1420 \\
1952 & 3373 \\
1954 & 8548 \\
\hline
\end{tabular}

Fuentes: Banco, Memorias, 1949, p. 129; 1950, p. 150; 1953, pp. 43, 29, 126 y 179, y 1955, p. 126. Incluye descuentos e hipotecas y adelantos en cuenta corriente.

nución, en algunos años, de la cantidad de bodegas en Mendoza (véase cuadro 3). Ahora bien, ¿cuál fue el impacto en los departamentos? En San Rafael se observa un aumento poco significativo de las bodegas que elaboraron sobre todo en la primera etapa, las cuales representaban $70 \%$ de las existentes. Se observa, en cambio, un aumento de la capacidad de vasija. Esto da cuenta del cierre de los establecimientos menos competitivos y la ampliación o modernización de la infraestructura de los que siguieron en el mercado, extendiendo su escala de producción y produciéndose un proceso de concentración productiva. En Lavalle, el número de bodegas que elaboraban se mantuvo constante, aunque el número representaba sólo 30\% de las existentes. Aumentó también en este departamento la capacidad de vasija. Esto sugiere que el municipio del Norte fue también beneficiado, aunque en menor medida, con créditos para ampliación y mejoramiento de sus establecimientos.

Este apoyo a las grandes y medianas bodegas, en un contexto en el que muchas habían dejado de producir -sobre todo pequeñas-, fue quizá lo que contribuyó al sostenimiento de la producción de vino ${ }^{104}$ en la provincia y en particular en San Rafael y Lavalle, con un crecimiento significativo hacia 1955 (véanse gráficas 2, 3 y 4). Sin embargo, no puede negarse que en ese crecimiento también influyó el apoyo del sistema crediticio a los pequeños productores, tanto viñateros como bodegueros ${ }^{105}$ puesto en evidencia, por ejemplo, a través de la vinculación del Banco de la Nación Argentina con las sociedades cooperativas. Entre 1946 y 1952 se registró

\footnotetext{
${ }^{104}$ En aquellos años en los que no se produjeron fenómenos climáticos.

${ }^{105}$ Girbal-Blacha, Mitos, 2003, p. 157.
} 
CUADRO 3. CANTIDAD DE BODEGAS Y CAPACIDAD DE VASIJAS

\begin{tabular}{ccccccc}
\hline & \multicolumn{3}{c}{ Bodegas que elaboraron } & \multicolumn{3}{c}{ Capacidad de vasijas. Miles de hl } \\
Años & Mendoza & San Rafael & Lavalle & Mendoza & San Rafael & Lavalle \\
& & & & & & \\
1951 & 882 & 217 & 4 & 16057278 & 1765662 & 57744 \\
1952 & 780 & 219 & 4 & 16955431 & 1830733 & 59235 \\
1954 & 765 & 235 & s. d. & 17466363 & 1934440 & s.d. \\
\hline
\end{tabular}

Fuentes: Elaboración propia con base en Banco, Vigésimo, 1954, p. 76; Guibourdenche, “San”, 1956, y Anuario, 1958.

una evolución importante del número de operaciones para las cooperativas agrícolas de la región vitivinícola argentina $(320 \%){ }^{106}$

Con el apoyo a estos sectores, es decir, a los pequeños productores, es destacable también la acción del gobierno provincial a través del Banco de Mendoza, ${ }^{107}$ que facilitó fondos a los viñateros para el cultivo de los viñedos, poda, desinfección, adquisición de abonos, madera, alambre, reposición de fallas y demás elementos del proceso productivo y de recolección. Los beneficios también fueron destinados a los bodegueros, otorgándoles créditos con prenda sobre la uva a industrializar -extensivos al vino producido-, con el objeto de sufragar los gastos de cosecha, acarreos, molienda, descube, desborre, fermentación, conservación, estacionamiento, traslado, fraccionamiento y expendio. ${ }^{108}$ Estos datos sugieren que el banco de la provincia se especializaba en capital de trabajo, mientras que la banca nacional se dedicaba además a la ampliación y mejoramiento de la infraestructura, tal como hemos visto.

Respecto a la relación entre el Banco de Mendoza y la actividad vitivinícola, su acción se caracterizó por el otorgamiento de fondos para el cultivo integral de viñedos y otras tareas, así como también para contribuir a solventar los gastos de todo el proceso productivo (véase cuadro 4).

De este cuadro se infiere que si para la provincia de Mendoza del total de los montos el 44\% iba destinado a la vitivinicultura en 1948, el municipio absorbía el 47.7\%. Además, en este rubro, San Rafael recibía un alto porcentaje de los montos de toda la provincia (8.4\%). Si bien las fuentes no especifican importes por actividad (primaria e industrial), estimamos que dentro del rubro "vitivinicultura" se destinaron sumas para la plantación

${ }^{106}$ Banco, Memorias, 1946, p. 163, y Banco, Memorias, 1952, p. 48.

${ }^{107}$ Institución que en 1934 se convirtió en sociedad mixta.

${ }^{108}$ Banco, Vigésimo, 1954, pp. 14-17; Decreto núm. 6 054, en Boletín, 1951, p. 6760; Decretos núms. 6645 y 827, en Boletín, 1952, pp. 695 y 1 010, respectivamente. 
Am. Lat. Hist. Econ., año 19, núm. 3, septiembre-diciembre, 2012, pp. 57-97

\section{CUADRO 4. PRÉSTAMOS DISTRIBUIDOS POR ACTIVIDAD ${ }^{a}$ (EN PESOS)}

\begin{tabular}{lrrrr}
\hline & \multicolumn{2}{c}{1948} & \multicolumn{2}{c}{1951} \\
Rubros & San Rafael & Mendoza & San Rafael & Mendoza \\
& & & & \\
Cuentas oficiales & s. d. & s. d. & s. d. & 175000 \\
$\begin{array}{l}\text { Vitivinicultura } \\
\text { Agricultura, ganadería }\end{array}$ & 3682858 & 43799760 & 6264169 & 67419548 \\
$\quad$ y granja & 535537 & 9048903 & 3274478 & 17787249 \\
$\begin{array}{l}\text { Fruticultura } \\
\text { Comercio }\end{array}$ & 219090 & 1539258 & 720839 & 2517743 \\
Empleados y & 2522749 & 28893390 & 3024358 & 37856421 \\
$\quad$ & & & & \\
$\quad$ profesionales & 222922 & 2634405 & 467351 & 3707412 \\
$\quad$ Propietarios urbanos & & & & \\
$\quad$ empleados y & & & & \\
$\quad$ profesionales & 114414 & 4032999 & 740870 & 4657540 \\
$\begin{array}{l}\text { Propietarios urbanos } \\
\text { Industrias diversas }\end{array}$ & 275634 & 2238944 & 310522 & 2997810 \\
Total & 417200 & 7197226 & 2207622 & 24431079 \\
& 7793223 & 99384889 & 15102549 & 161549805 \\
\end{tabular}

a Incluye documentos descontados, adelantos en cuenta corriente y letras compradas.

Fuentes: elaboración propia con base en Banco, Memoria, 1948 y 1951, s. p.

de viña. Hacia 1951 se observa un salto de casi 55\% de los préstamos a la actividad vitivinícola en Mendoza ${ }^{109}$ y de $70 \%$ en San Rafael, así como también del porcentaje que este representó en el conjunto provincial. Sin embargo, no debemos dejar de mencionar el impulso cobrado por la fruticultura con un ascenso significativo.

Dado que no poseemos datos en cuanto a los montos otorgados por el banco provincial al departamento de Lavalle, hemos tomado la información de un departamento de características similares, como fue Eva Perón (actual La Paz). En 1948, este recibió sólo 3\% del total de préstamos, mientras que San Rafael 27\%. Si bien los porcentajes destinados a la vitivinicultura eran altos en La Paz $(60 \%)$, tuvo muy poca participación en relación con la provincia $(1.2 \%)$ y otros departamentos. Sin embargo, hacia 1951 se observa, al igual que en San Rafael, un aumento de 70\% de los montos a invertir, lo que demuestra un mayor impulso dado a esta actividad en un

${ }^{109}$ Estos porcentajes persistieron en los años posteriores. 
departamento de escaso desarrollo, ${ }^{110}$ aunque continuó con poca participación en el contexto provincial.

Podemos considerar entonces que la política de préstamos, junto con la de irrigación mencionada anteriormente, tuvo resultados positivos en la plantación de viñas, ya que la superficie cultivada logró extenderse considerablemente en los ámbitos municipales. Los efectos positivos también se pueden observar en la producción de uva y vino entre 1954 y 1955 donde alcanzaron proyecciones extraordinarias, aunque con representaciones diferentes en el contexto provincial (véanse gráficas 3 y 4 ).

\section{Defensa de los pequeños productores: el seguro agrícola y el fomento del cooperativismo}

Una de las medidas instrumentadas en defensa de los pequeños productores fue aquella relacionada con las contingencias climáticas. Concretamente, entre 1949 y 1954, la agricultura de la provincia de Mendoza se vio perjudicada por la presencia de las heladas tardías y la caída de granizo. ${ }^{111}$

Los datos del cuadro 5 ejemplifican las pérdidas sufridas a causa de la caída de granizo en los periodos 1951-1952, 1952-1953 y 1953-1954. Siguiendo con la gráfica 2, luego de 1949 la producción en el departamento de San Rafael se recuperó significativamente, llegando casi a los niveles de 1947. Este crecimiento se mantendría solo hasta 1951, ya que a partir de 1952-1953 se produciría una sensible disminución provocada por la caída de granizo en este periodo y durante la cosecha de 1953-1954. Según los registros del Instituto del Seguro Agrícola, en la temporada 1952-1953 las pérdidas totalizaron 929595 quintales de uva en toda la provincia, participando San Rafael con 30\% (291 334 quintales). ${ }^{112}$ En departamentos como Lavalle, las escasas pérdidas por granizo en la temporada 1952-1953 (0.81\%) no impidieron el crecimiento de la producción, aunque entre 1953 y 1954 sufrió un descenso ya que los daños fueron mayores, casi alcanzando a la provincia y superando los porcentajes de San Rafael.

${ }^{110}$ Banco, Memoria, 1948 y 1951, s. p.

111 "Sur de Mendoza, tierra de buenos vinos", Olimpiadas nacionales de contenido educativo en Internet, Escuela de Agricultura de Colonia Alvear Oeste, 1999, en <www.oni.escuelas.edu.ar/ olimpi99/tierradebuenosvinos/fermecont\%C3\%AD.htm >. [Consulta: 10 de noviembre de 2010]; Instituto Financiero Agrario, 1963, en Marianetti, Racimo, 1965, p. 201. A este fenómeno se le sumaron las heladas -principalmente las del 6 de octubre de 1953 y septiembre de 1954-, véase Guibourdenche, "San", 1956.

112 Gobierno, Mensaje, 1954, p. 115. 
Am. Lat. Hist. Econ., año 19, núm. 3, septiembre-diciembre, 2012, pp. 57-97

CUADRO 5. PORCENTAJE DE DAÑOS POR GRANIZO EN VIÑEDOS

\begin{tabular}{ccccccccc}
\hline \multicolumn{1}{c}{$\begin{array}{c}\text { 1951-1952 } \\
\text { San }\end{array}$} & & \multicolumn{3}{c}{ 1952-1953 } & \multicolumn{3}{c}{ 1953-1954 } \\
Mendozan & Rafael & Lavalle & Mendoza & Rafael & Lavalle & Mendoza & Rafael & Lavalle \\
& & & & & & & & \\
7 & s.d. & s. d. & 8.5 & 17.8 & 0.81 & 9.91 & 7.29 & 9 \\
\hline
\end{tabular}

Fuentes: elaboración propia con base en Gobierno, Mensaje, 1953, p. 64, e Instituto Financiero Agrario, 1963, en Marianetti, Racimo, 1965, p. 201.

A este fenómeno se le sumaron las heladas -principalmente las del 6 de octubre de 1953 y septiembre de 1954-, ${ }^{113}$ que afectaron las plantaciones en plena época de floración. Debe aclararse que estos accidentes climáticos afectaron en el departamento de San Rafael conjuntamente el volumen de la cosecha de uva y de frutas.

En 1951 se sancionó la Ley provincial núm. 1963 que creaba el Seguro Agrícola. ${ }^{114}$ En un comienzo, el gobierno sólo ampararía la producción vitícola, organizando de inmediato el seguro contra los riesgos del granizo. Fue así que a partir de la ley mencionada, y frente a una larga serie de siniestros de granizo -comenzada en el mes de octubre de 1951 hasta las últimas semanas de la cosecha de 1952-, se declaró cubierto el seguro de los cultivos vitícolas también correspondientes a las cosechas 1952-1953, disposición de singular importancia desde el momento en que se anticipó la aplicación del seguro a la producción antes de hacerse efectivo el pago de la prima. ${ }^{115}$ Podemos decir que esta medida ponía en evidencia el avance del Estado de Bienestar en la provincia, dado que su acción significaba la defensa y resguardo de los agricultores contra todo riesgo proveniente de estas contingencias climáticas.

El fomento de las sociedades cooperativas fue otra de las estrategias seguidas por el Estado para lograr el aumento de la producción, siendo significativa su evolución durante el gobierno peronista. ${ }^{116}$ En Argentina,

${ }^{113}$ En 1954 heló desde abril y se registraron 19 heladas en julio y cinco en septiembre, en Guibourdenche, "San”, 1956. Según tenemos registro, respecto al periodo 1952-1953 se pagaron las indemnizaciones correspondientes, véase Gobierno, Mensaje, 1954, p. 78.

${ }^{114}$ La Ley núm. 1963 indemnizaba por pérdidas causadas, con un importe igual en promedio al costo de la producción dañada. En un primer momento, la aplicación de esta ley estuvo a cargo de la Dirección de Seguro Agrícola, aunque la Ley modificatoria núm. 2071 de 1952 creó el Instituto de Seguro Agrícola, por esta legislación se establecieron las funciones del organismo, las bases para el monto de las indemnizaciones, la constitución de los fondos, etc., véanse Leyes núms. 1963 y 2 071, en Boletín, 1951 y 1952, respectivamente.

115 Ibid.

${ }^{116}$ Véanse Gutiérrez, "Peronismo", 2002, y Olivera, Cooperativismo, 2006, p. 21. 
los tipos de cooperativas existentes entre 1948 y 1950 expresaban la gran variedad de actividades, siendo las más importantes por su número las tamberas (369), agrícolas (225), vinifrutícolas-hortícolas (32), algodoneras (29), entre otras. Las cooperativas vitivinícolas en todo el país tuvieron una evolución positiva en el periodo, aumentando $76 \%$ entre 1947 y $1951 .{ }^{117}$ Si bien no poseemos información específica de la provincia de Mendoza, según los datos que brinda la prensa, entre 1953 y 1955 se formaron alrededor de 30 cooperativas de viñateros sin bodega. ${ }^{118}$ Creemos que esta era una de las soluciones al problema de estos sectores, principalmente cuando la uva era objeto de especulaciones por parte de los grandes elaboradores.

Como ya se ha desarrollado en el presente artículo, como consecuencia del "ordenamiento vitivinícola", se produjo una concentración de la producción en los grandes establecimientos, lo que traía aparejada la necesidad de ampliación de la capacidad de vasija vinaria, algo que el Estado intentó remediar a través de la línea de créditos. Sin embargo, el gobierno ofreció soluciones también destinadas a los viñateros y pequeños productores agroindustriales (trasladistas).

Una de las alternativas propuestas por el gobierno para que estos pudieran elaborar y comercializar sus propios productos, fue la construcción de bodegas regionales cooperativas. ${ }^{119}$ De esta manera, se pretendía incrementar la producción vínica (al aprovechar integralmente la materia prima), proporcionar al viñatero sin bodega la seguridad de la elaboración de las uvas, impedir la especulación según las condiciones del mercado y responder a la necesidad de obtener vinos estacionados y al problema de la falta de vasijas existente principalmente en las zonas del sur y este de la provincia de Mendoza. ${ }^{120}$ Aunque durante el peronismo estas bodegas no llegaron a construirse ${ }^{121}$ la situación de estos subsectores logró remediarse mediante la adquisición por parte del Estado de Bodegas y Viñedos

${ }^{117}$ Olivera, Cooperativismo, 2006, p. 28.

${ }^{118}$ Aunque se destaca que la región pampeana fue el núcleo central del cooperativismo argentino. Ibid., p. 27.

${ }^{119}$ Era una antigua idea de la industria vitivinícola, surgida frente a la presencia del viñatero sin bodega, productor afectado principalmente en épocas de crisis, cuando la uva fue objeto de especulaciones que los obligaban a vender su producción a precios que no cubrían los costos, véase "Las bodegas regionales", Los Andes, 25 de julio de 1949, p. 6. Un antecedente de bodegas regionales y cooperativas lo constituyó la sanción de las Leyes núms. 758 y 759 de 1919, durante la gestión de José Néstor Lencinas, que intentó solucionar a través de ellas la situación de los viñateros sin bodega, pero también mediante préstamos a los productores para construir o ampliar establecimientos y la instalación de fábricas cooperativas. También se propuso la creación de cooperativas regionales para evitar la "trustificación". Además, durante la década de 1930 las Leyes núms. 1 071, 1 072, 1073 y 1078 de diciembre de 1933, otorgaron facilidades para la construcción de bodegas regionales, de cooperativas privadas o asociadas al Estado, en Mateu, "Vitivinicultura", 2005. Hay que destacar que nunca se concretaron estos proyectos.

120 "Las bodegas regionales", Los Andes, 25 de julio de 1949, p. 6.

${ }^{121}$ Véase Martín, Estado, 1992, p. 196. 
Giol en $1954{ }^{122}$ En contra de prácticas "colusivas" entre las empresas de mayor tamaño para acordar precios en el mercado de vino de traslado ${ }^{123}$ y del monopolio y la concentración, fueron finalmente beneficiados los viñateros (sin bodega) y los productores agroindustriales (trasladistas) mediante operaciones de compra de uva y vino con intención de regular los precios. ${ }^{124}$ La compra de este establecimiento vitivinícola significaba no sólo la culminación de un largo proceso gestado por la situación de desequilibrio del mercado de vinos, sino también una intervención más acentuada del Estado en los mercados vitivinícolas, evidenciándose así su participación empresarial.

\section{CONSIDERACIONES FINALES}

La presente investigación constituye una contribución a los estudios de las economías provinciales de la República Argentina durante el periodo 1946-1955. A través del presente trabajo hemos analizado la injerencia del gobierno peronista tanto nacional como provincial en la industria vitivinícola mendocina, así como también hemos logrado un primer acercamiento a la relación entre las políticas y los diferentes agentes, y los efectos de las mismas en el comportamiento de la actividad de Mendoza en general, como de dos departamentos diferentes, en particular. Uno, en el que la industria vitivinícola constituía una de sus actividades económicas principales y más desarrolladas, y el otro, en el que se hallaba en estado incipiente. Este estudio nos permitió medir el grado de importancia de la vitivinicultura en San Rafael, así como también obtener un panorama de la distribución espacial de las políticas públicas.

Las políticas de ordenamiento, que evitaron, por un lado, el aumento excesivo de los precios del vino en defensa de los consumidores, produjeron, por otro lado, efectos negativos sobre algunos subsectores de la actividad y cambios en el papel que ocupaban en la cadena productiva, dado el contexto inflacionario que afectaba a toda la economía del país. El cierre de establecimientos que elaboraban vino de traslado y la concentración de la producción en un grupo reducido de bodegas, fue el ejemplo más

\footnotetext{
${ }^{122}$ En 1954, por la Ley núm. 2 301, quedó aprobado un convenio entre Mendoza y el Banco Crédito Español del Río de la Plata por el que la provincia accedió a $51 \%$ del paquete accionario de Bodegas y Viñedos Giol. Ley núm. 2 301, en Boletín, 1954, p. 1326.

${ }^{123}$ Olguín, "Intervención", 2008, p. 73.

${ }^{124}$ Aunque según la opinión del ministro de Hacienda Benedicto Cáplan, el principal motivo de la compra de Giol era de carácter financiero. Se pensaba sanear las finanzas de la empresa y consolidar su estructura económica para crear una fuente de recursos adicional a la tributaria para financiar proyectos del gobierno, en ibid., p. 75.
} 
evidente de esta situación. Sin embargo, a pesar de los perjuicios que la fijación de precios topes trajo aparejada, los pequeños productores recibieron el apoyo del Estado a través de otras medidas, apoyo que adquirió mayor intensidad a finales del gobierno.

En el presente trabajo, hemos señalado que en Mendoza y San Rafael la escasez de vino a fines de la década de 1940 se debió principalmente a las pérdidas de uva causadas por los fenómenos climáticos. Sin embargo, pudimos comprobar que los periodos de recuperación y crecimiento no fueron sólo consecuencia de la ausencia de estos fenómenos, sino también de políticas de incentivo a la producción. Así, pudimos observar no sólo los resultados positivos que las mismas produjeron en ambos departamentos, sobre todo en los últimos años del periodo peronista, sino también los beneficios que significaron para los distintos actores económicos en juego. Entre las políticas aplicadas, se encontraban aquellas orientadas tanto al aumento de la superficie cultivada como de la producción primaria e industrial. Se pudo verificar una ampliación y perfeccionamiento de la legislación referida a irrigación y la concreción de un importante plan de obras de riego.

En una economía con altos índices de inflación, la política de crédito oficial fue una de las herramientas utilizadas para evitar la disminución de la producción, tanto primaria como industrial. El otorgamiento de préstamos no sólo estuvo destinado a la adquisición de nuevas tierras y a sufragar gastos del proceso productivo, sino también a la ampliación y modernización de la infraestructura, gracias a lo cual las grandes y medianas bodegas de ambos municipios lograron aumentar sus escalas de producción. Sin embargo, la implementación del Seguro Agrícola, el otorgamiento de préstamos individuales y el fomento de las cooperativas fueron políticas estatales tendentes a favorecer a los pequeños productores. Una modalidad de cooperativismo propulsada, fue la construcción de bodegas regionales mediante las cuales los viñateros sin bodega se convertirían en productores directos de vino. Aunque este proyecto quedó trunco, el logro parcial de los objetivos fue alcanzado a través de la constitución de una bodega estatal, concretada a través de la adquisición, por parte del Estado provincial, de las Bodegas y Viñedos Giol. La función de esta bodega era comprar la uva a pequeños viñateros y prestar servicios de elaboración, poniendo además a disposición de los pequeños bodegueros sus canales de comercialización. Esta defensa de los pequeños viñateros y productores agroindustriales, dio cuenta entonces de que en el objetivo del Estado de aumentar la producción, estos sectores no podían estar ausentes. Pero también es importante destacar que dicho apoyo significó un cambio sustancial de la participación del Estado, que de promotor se convirtió en em- 
presario, evidenciándose así un avance importante del Estado de Bienestar en la provincia de Mendoza.

El progresivo aumento del área de viñedos en San Rafael y Lavalle y el crecimiento de la producción primaria e industrial, cuyo record fue alcanzado en el año 1955, nos demostró la exitosa aplicación de las políticas de fomento implementadas. San Rafael logró un ascenso de casi 80\% en la uva vinificada y el vino producido respecto a 1954, mientras que Lavalle superó el $100 \%$, lo que muestra el proceso expansivo en tal rubro. Sin embargo, no debemos olvidar la escasa representatividad que la producción de este último tuvo en el total provincial. Es decir, en los pocos años de que dispusimos datos, hemos podido observar que el comportamiento de la actividad en Lavalle fue relativamente positivo, dado los aumentos mencionados, y si bien en el último año del gobierno peronista aumentó su participación económica en el contexto provincial, las bases de las que partía no podían aproximarlo a los niveles adquiridos por San Rafael. En ello, seguramente incidió el hecho de que algunas políticas, como por ejemplo la crediticia, no tuvieran una distribución igualitaria, percibiendo algunos departamentos muy poca ayuda financiera en relación con otros. Esto sugirió que mediante esta distribución, el gobierno potenció aquellos territorios con una industria vitivinícola más desarrollada y con posibilidades de repercutir favorablemente en la economía provincial. Aunque cabe indagar acerca de la temática, podemos pensar también que en la distribución espacial de dichas medidas influyó el factor político, es decir, se tendió a beneficiar a aquellos territorios que poseían mayor peso electoral.

\section{FuENTES CONSULTADAS}

\section{Archivos}

AGN Archivo General de la Nación, Buenos Aires, Argentina.

\section{Hemerografía}

El Comercio, San Rafael-Mendoza, Argentina.

Los Andes, Mendoza, Argentina. 


\section{Bibliografía}

Álvarez, Graciela Yamile, "Mendoza hacia 1955. La revolución libertadora. La historia a través de sus testigos", Revista de Estudios Regionales, Universidad Nacional de Cuyo, núm. 10, 1993, Mendoza, pp. 173-224.

"En torno de los orígenes del peronismo mendocino" en DARÍO MACOR y CÉSAR TCACH (eds.), La invención del peronismo en el interior del país, Santa Fe, Universidad Nacional del Litoral, 2003.

Anales de la legislación argentina, Buenos Aires, Ediciones La Ley, 1955, tt. IV-XV.

Anuario. Sintesis estadística y geográfico-económica, Mendoza, Ministerio de Economía/ Instituto de Investigaciones Económicas y Tecnológicas, años 1952-1958.

Asociación Vitivinícola Argentina, "Problemas de la industria vitivinícola”, Revista Vinos, Viñas y Frutales, Buenos Aires, 1947, pp. 161-162.

"Ante el pedido de fijación de precios máximos", Revista Vinos, Viñas y Frutales, Buenos Aires, 1948, pp. 380-383.

Banco de la Nación Argentina, Memorias y balances, Buenos Aires, s. e., 1946-1956.

Banco de MendozA, Memoria y balance general, Mendoza, Talleres Gráficos Jorge Best, 1948.

Memoria y balance general, Mendoza, Talleres Gráficos Jorge Best, 1951.

, Vigésimo aniversario, 1934-1954, Mendoza, Talleres Gráficos Jorge Best, 1954.

Banco Industrial de la República Argentina. Memoria y balance, 1955, Buenos Aires, Banco Industrial de la República Argentina, 1956.

Bacolla, Natacha, "Política, administración y gestión en el peronismo santafecino, 1946-1955” en DARÍO MACOR y CÉSAR TCACH (eds.), La invención del peronismo en el interior del país, Santa Fe, Universidad Nacional del Litoral, 2003.

Barrio de Villanueva, Patricia, Hacer el vino. Empresarios vitivinícolas y Estado en Mendoza (1900-1912), Rosario, Prohistoria Ediciones, 2010.

(dir.), Crisis y transformaciones en la vitivinicultura mendocina (1890-1955), Mendoza, Universidad Nacional de Cuyo, 2010.

"Controles estatales a la industria del vino en Mendoza, 1890-1914", H-industri@, Revista de Historia de la Industria, los Servicios y las Empresas de América Latina, Universidad de Buenos Aires, año 4, núm. 7, segundo semestre de 2010, Argentina, <http://www.hindustria.com.ar/images/client_gallery//HindustriaNro7Barrio.pdf>. [Consulta: 5 de mayo de 2011.]

Belini, Claudio, "Estado y política industrial durante el primer peronismo (19461955)" en Patricia Berrotarán et al., Sueños de bienestar en la nueva Argentina: estado y políticas públicas durante el peronismo (1946-1955), Buenos Aires, Imago Mundi, 2004 .

y MARCelo Rougier, Los dilemas de la historiografía económica sobre el peronismo: certezas dudosas, vacios persistentes. Aportes para la construcción de una agenda de 
Am. Lat. Hist. Econ., año 19, núm. 3, septiembre-diciembre, 2012, pp. 57-97

investigación. La historia económica argentina en la encrucijada. Balances y perspectivas, Buenos Aires, Prometeo, 2006.

Berrotarán, Patricia, "La planificación como instrumento" en Patricia BerrotaRÁN et al., Sueños de bienestar en la nueva Argentina: estado y políticas públicas durante el peronismo (1946-1955), Buenos Aires, Imago Mundi, 2004.

Boletín Oficial de la Provincia de Mendoza, Mendoza, Argentina, años de consulta 1941-1954.

BorCosque, LÍA, "Los empresarios del vino y la vitivinicultura sanjuanina: el Centro de Bodegueros y Exportadores de San Juan" en Javier Balsa, Graciela Mateo y Silvia Ospital (comps.), Pasado y presente en el agro argentino, Buenos Aires, Lumiere, 2008.

"El accionar peronista y vitivinicultura en San Juan (1943-1951)" en I Jornadas Interdisciplinarias de Investigaciones Regionales, Mendoza, Unidad de Estudios Regionales Interdisciplinarios-Consejo Nacional de Investigaciones Científicas y Técnicas, 2009.

CANTARelli, Andrea, "Contratistas de plantación: agentes geográficos en los comienzos de la viticultura moderna en San Rafael (Mendoza) 1880-1914" en Anuario del Centro de Estudios Históricos Prof. Carlos S. A. Segreti, núm. 9, Córdoba, Centro de Estudios Históricos Prof. Carlos Segreti, 2011.

Censo agropecuario de 1947, Mendoza, Gobierno de Mendoza, Ministerio de Economía, Obras Públicas y Riego, Instituto de Investigaciones Económicas y Tecnológicas, 1949.

Censo Nacional Agropecuario de 1960. Resultados provisorios obtenidos de la compilación efectuada para por el I.E.T., Mendoza, Ministerio de Economía, Obras Públicas y Riego/Instituto de Investigaciones Económica y Tecnológica, 1962.

Constitución de la Provincia de Mendoza, Mendoza, Imprenta Oficial, 1916.

Cremaschi, Ángel, "Los problemas de riego en Mendoza", Revista Vinos, Viñas y Frutas, Buenos Aires, 1947.

Cueto, Adolfo, "Los gobiernos peronistas en Mendoza" en XI Congreso Nacional y Regional de Historia Argentina, Academia Nacional de la Historia, Buenos Aires, 2001.

"Decreto núm. 5 851", Revista Vinos, Viñas y Frutas, Buenos Aires, Asociación de la Industria Vitivinícola Argentina, 1949.

Departamento General de Irrigación, Memoria, 1946, Mendoza, Talleres Gráficos Jorge Best, 1949. , Memoria, 1947, Mendoza, Talleres Gráficos Jorge Best, 1950. , Memoria, 1948, Mendoza, Talleres Gráficos Jorge Best, 1951. Memoria, 1952, Mendoza, Talleres Gráficos Jorge Best, 1954.

"Dirección de Control y Fomento de la Producción, Industria y Comercio", Revista de la Cámara de Comercio, Industria y Agricultura de San Rafael, Mendoza, 1946.

Dirección General de Investigaciones, Estadística y Censos, IV Censo General de la Nación, Buenos Aires, s. e., 1947, tt. I y III. 
Dorfman, Adolfo, Cincuenta años de industrialización en la Argentina. 1930-1980. Desarrollo y perspectivas, Buenos Aires, Ediciones del Solar, 1983.

Ferrer, Aldo, La economía argentina. Desde sus orígenes hasta principios del siglo XXI, Buenos Aires, Fondo de Cultura Económica, 2004.

García de Martín, Griselda y Gladys Molina de Buono, "Hacia una metodología integrada para la planificación del servicio educativo, Departamento de Lavalle", Boletín de Estudios Geográficos, Universidad Nacional de Cuyo, vol. xxv, núm. 89, 1993, Argentina, pp. 191-226.

Garzón Rogé, Mariana, “¿Hermosa, optimista y rosada ficción? La obra del coronel Perón desde la perspectiva de una federación obrera mendocina”, Revista de la Asociación Argentina de Especialistas en Estudios de Trabajo, núms. 39-40, segundo semestre de 2010, Argentina, pp. 156-185.

"Dispersión, lealtad y pragmatismo: itinerario de la experiencia sindical de los vitivinícolas argentinos" en Ana María MATEu (comp.), Vinos y competitividad agroindustrial. Un largo camino, Mendoza, Instituto de Ciencias Humanas, Sociales y Ambientales, 2011.

Las relaciones capital-trabajo en la mira de un Estado provincial, Mendoza, 1916 1946, en la construcción de las instituciones laborales en la Argentina, 1907-1955, Buenos Aires, Edhasa, 2011.

Girbal-Blacha, Noemí, "Políticas públicas para el agro se ofrecen. Llamar al Estado peronista (1943-1955)”, Mundo Agrario. Revista Digital de Estudios Rurales, Universidad Nacional de La Plata, núm. 5, segundo semestre de 2002, <http://mundoagrarioold.fahce.unlp.edu.ar/nro5/Girbal.htm>. [Consulta: 20 de junio de 2011.] Mitos, paradojas y realidades en la Argentina peronista (1946-1955). Una interpretación histórica de sus decisiones político-económicas, Buenos Aires, Universidad Nacional de Quilmes, 2003.

"Economía azucarera tucumana, empresarios y crédito en tiempos del Estado peronista (1946-1955)" en DARíO MACOR y CÉSAR TCACH (eds.), La invención del peronismo en el interior del país, Santa Fe, Universidad Nacional del Litoral, 2003. et al., Las miradas del pasado. Las economías agrarias del interior ante la crisis de 1930, Buenos Aires, Editorial Nacional, 2007.

Gobierno de Mendoza, Mensaje del gobernador a la Legislatura, Mendoza, Talleres Gráficos Jorge Best, 1948.

Best, 1949

Mensaje del gobernador a la Legislatura, Mendoza, Talleres Gráficos Jorge Mensaje del gobernador a la Legislatura, Mendoza, Talleres Gráficos Jorge Best, 1950.

Mensaje del gobernador a la Legislatura, Mendoza, Talleres Gráficos Jorge Best, 1952.

, Mensaje del gobernador a la Legislatura, Mendoza, Talleres Gráficos Jorge Best, 1953. 
Am. Lat. Hist. Econ., año 19, núm. 3, septiembre-diciembre, 2012, pp. 57-97

Mensaje del gobernador a la Legislatura, Mendoza, Talleres Gráficos Jorge Best, 1954.

Boletín Informativo, síntesis estadística de la provincia de Mendoza, anuario estadístico (1952-1955), Mendoza, Talles Gráficos Jorge Best, 1955.

Gobierno de Mendoza, Secretaría de Informaciones, Agua, vivienda y salud. Tres años de labor justicialista, Mendoza, 1952.

GonZÁles ARroyo, IGNACiO, Historia contemporánea de Mendoza a través de sus gobernadores: 1932-1966, Mendoza, Junta de Estudios Históricos de Mendoza, 1996.

Guibourdenche de Cabezas, Martha, "San Rafael visto a través de la estadística”, Revista de la Facultad de Ciencias Económicas de la Universidad Nacional de Cuyo, Mendoza, 1956.

GutiÉRrez, TALÍA, “El peronismo y el 'mundo agrario'. Una visión sobre el agro argentino, 1949-1955”, Mundo Agrario. Revista Digital de Estudios Rurales, Universidad Nacional de La Plata, núm. 4, primer semestre de 2002, <http://www.mundoagrario.unlp.edu.ar/numeros/no-18-1er-sem-2009/desarrollo-cientifico-e-industriavitivinicola-moderna-origenes-y-consolidacion-de-la-estacion-enologica-de-mendoza-argentina-1904-1920>. [Consulta: 20 de marzo de 2009.]

Hirschegger, Ivana, "Políticas públicas peronistas y su impacto en el desarrollo económico y social de los municipios mendocinos (1946-1955)", tesis doctoral, Argentina, Universidad Nacional de Cuyo, 2009.

"Agroindustrias y políticas públicas. El caso de la vitivinicultura mendocina durante el peronismo clásico (1946-1955)", Prohistoria, año XIV, núm. 14, primavera de 2010, Rosario, pp. 49-73.

"Estrategias estatales en la vitivinicultura mendocina. Políticas de ordenamiento y de fomento a la producción (1946-1955)" en PATRICIA BARRIO DE VILLANUEVA (dir.), Crisis y transformaciones en la vitivinicultura mendocina (1890-1955), Mendoza, Universidad Nacional de Cuyo, 2010.

Jáuregui, Aníbal, "La planificación económica en el peronismo (1945-1955)”, Revista Prohistoria, año IX, núm. 9, primavera de 2005, Rosario, Argentina, pp. 15-40.

MaCOR, DARÍo y CÉSAR TCACH, La invención del peronismo en el interior del país, Santa Fe, Universidad Nacional del Litoral, 2003.

Marianetti, Benito, Los problemas de Cuyo, Buenos Aires, Lautaro, 1947.

La cuestión vitivinícola, Mendoza, s. e., 2a. ed., 1952.

El racimo y su aventura. La cuestión vitivinícola, Buenos Aires, Platina, 1965.

Martín, José Francisco, Estado y empresas. Relaciones inestables, políticas estatales, y conformación de una burguesía industrial regional, Mendoza, Universidad Nacional de Cuyo, 1992.

Mateu, Ana María, "La vitivinicultura mendocina en los años treinta: entre el derrame de vinos y la profusión de estudios sobre la crisis", en III Congreso de Historia Vitivinícola Uruguaya, I Congreso de Historia Vitivinícola Regional, noviembre de 2005 . 
y PAtricia Olguín, "El problema no es intervenir sino cómo. Las posturas de la AVA frente al gobierno peronista” en XX Jornadas de Historia Económica, Asociación Argentina de Historia Económica, Universidad Nacional de Mar del Plata, 2006 (en CD-ROM).

Melón Pirro, César y Nicolás Quiroga (eds.), El peronismo bonaerense: partido y prácticas políticas, 1946-1955, Mar del Plata, Ediciones Suárez, 2006.

Oficina de Prensa e Informaciones del Poder Ejecutivo, Perón cumple. Agua, vivienda y salud. Tres años de labor justicialista, Mendoza, 1952.

Olguín, PATRICIA, "Políticas públicas y empresas vitivinícolas: la privatización de Giol y la conformación de Fecovita. $1^{\text {a }}$ parte: la creación de la Bodega Estatal” en Actas IV Jornadas Interdisciplinarias Estudios Agrarios y Agroindustriales, Buenos Aires, 2005 (en CD-ROM).

"La intervención estatal en los mercados vitivinícolas. La función de regulación de las Bodegas y Viñedos Giol, Mendoza, Argentina (1954-1974)", Territorios del Vino, Universidad de la República, año II, núm. 2, junio de 2008, Montevideo, pp. $67-107$.

Olivera, Gabriela (comp.), Cooperativismo agrario: instituciones, políticas públicas y procesos históricos, Córdoba, Ferreira Editor, 2006.

Ospital, María Silvia, "Políticas reguladoras en la vitivinicultura argentina. Crisis e intervención del Estado. 1930-1940" en III Congreso de Historia Vitivinícola Uruguaya, I Congreso de Historia Vitivinícola Regional, 2005.

Pérez Romagnoli, Eduardo, Los guardianes del Baco. Artesanos toneleros e industrias incipientes de vino en Mendoza y San Juan (1885-1930), Rosario, Prohistoria Ediciones, 2008.

Más allá del vino. Industrias derivadas de la vitivinicultura moderna en Mendoza y San Juan. Dinámicas de una región en formación (1885-1930), Rosario, Prohistoria Ediciones, 2010.

PodestÁ, RicARdo, "La intervención del Estado en la vitivinicultura" en EDGARDO Díaz Araujo et al., Crisis vitivinícola. Estudios y propuestas para su solución. Anexo legislativo, Mendoza, Universidad de Mendoza/Idearium, 1982.

Poder Ejecutivo Nacional, "Decreto núm. 3 134”, Revista Vinos, Viñas y Frutas, Asociación de la Industria Vitivinícola Argentina, 1946, Buenos Aires, pp. 450-451.

Ministerio de Economía y Trabajo, Estadística vitivinícola, Mendoza, Instituto Nacional de Vitivinicultura, 1968.

Pozo, José Del, Historia del vino chileno. Desde 1850 hasta hoy, Santiago de Chile, Editorial Universitaria, 1998

Presidencia de la Nación, Primer Plan Quinquenal, Buenos Aires, 1947.

Segundo Plan Quinquenal Provincial 1953-1957 (Ley núm. 2 146), Mendoza, Talleres Gráficos Jorge Best, 1953.

Secretaría Técnica, Plan de gobierno, 1947-1951, Buenos Aires, Talleres Gráficos de la Presidencia Nacional de Buenos Aires, 1946, t. I. 
Presidencia de la Nación, Subsecretaría de la Presidencia, Segundo plan quinquenal, Buenos Aires, Talleres Gráficos de la Presidencia Nacional de Buenos Aires, 1952.

Richard-Jorba, Rodolfo, Poder, economía y espacio en Mendoza (1850-1900). Del comercio ganadero a la agroindustria vitivinícola, Mendoza, Universidad Nacional de Cuyo, 1998.

, "Formación, crisis y reorientaciones de la vitivinicultura en Mendoza y San Juan, 1870-2000. Aportes para el estudio del sector en la Argentina”, Boletín Geográfico, Universidad Nacional del Cuyo, año XXVIII, núm. 28, diciembre de 2006.

"Crisis y transformaciones recientes en la región vitivinícola argentina. Mendoza y San Juan, 1970-2005", Revista de Investigación Científica, Centro de Investigación en Alimentación y Desarrollo, vol. 16, núm. 31, enero-junio de 2008, México, pp. 81-123.

Empresarios ricos, trabajadores pobres. Vitivinicultura y desarrollo en Mendoza (1870-1918), Rosario, Prohistoria Ediciones, 2010.

Riveros, José, “Disminución de la producción de uva”, Revista Vinos, Viñas y Frutas, Buenos Aires, 1946.

Rodríguez VÁzQuez, Florencia, "Desarrollo científico e industria vitivinícola moderna: orígenes y consolidación de la Estación Enológica de Mendoza (Argentina), 1904-1920", Mundo Agrario. Revista Digital de Estudios Rurales, Universidad Nacional de La Plata, vol. 9, núm. 18, primer semestre de 2009, <http://www. mundoagrario.unlp.edu.ar/numeros/no-18-1er-sem-2009/desarrollo-cientifico-eindustria-vitivinicola-moderna-origenes-y-consolidacion-de-la-estacion-enologicade-mendoza-argentina-1904-1920>. [Consulta: 10 de septiembre de 2010.]

"La educación agrícola en una economía regional: el aporte de la Escuela Nacional de Vitivinicultura en Mendoza y San Juan (1900-1920)", Prohistoria, vol. 16, julio-diciembre de 2011, Rosario.

Rougier, MARCELO, La política crediticia del Banco Industrial durante el primer peronismo (1944-1955), Buenos Aires, Centro de Estudios Económicos de la Empresa y el Desarrollo-Universidad de Buenos Aires, 2001.

Rubinstein, Gustavo, Los sindicatos azucareros en los orígenes del peronismo tucumano, Tucumán, Universidad Nacional de Tucumán, 2006.

Tella, Guido Di y Manuel Zymelman, Las etapas del desarrollo económico argentino, Buenos Aires, Editorial Universitaria de Buenos Aires, 1967.

Vicepresidencia de la Nación Argentina, Consejo Nacional de Posguerra, "Documentos para la historia social y económica Latinoamericana", Desarrollo Económico, Revista de Ciencia Social, Instituto de Desarrollo Económico y Social, vol. 20, núm. 77, 1980, Buenos Aires, pp. 117-120. 